\title{
Modeling the Surface Heat Flux Response to Long-Lived SST Anomalies in the North Atlantic
}

\author{
S. B. Power, R. KleEman, R. A. Colman, AND B. J. MCAvaney \\ Bureau of Meteorology Research Centre, Melbourne, Australia
}

(Manuscript received 1 August 1994, in final form 30 December 1994)

\begin{abstract}
An atmospheric general circulation model (AGCM), a simplified atmospheric model (SAM) of surface heat flux, and various idealized analytic models have been used to investigate the atmospheric response over the North Atlantic to SST anomalies, including a general cooling associated with a weakened thermohaline circulation. Latent heating dominates the surface heat flux response, while sensible heating plays an important secondary role. The total heat flux response is weaker than presumed in recent studies using ocean models under highly idealized surface boundary conditions. This implies that stability of the thermohaline circulation to high-latitude freshening in more sophisticated coupled systems (that incorporate either AGCMs or models like SAM) will be increased.

All three kinds of atmospheric models exhibit nonrestorative behavior away from the anomaly peak that is primarily associated with the advection of cooled air eastward. This simple picture is complicated in the AGCM by the fact that the winds weaken over the SST anomaly, which helps to moderate the response.

Analytic models for atmospheric temperature forced using imposed surface temperature anomalies highlight conditions under which a nonrestorative response can arise. Previous work has shown that the length scale of spatially periodic anomalies partially determines the magnitude of the response in a diffusive atmosphere. Here the authors show that this scale dependence has much wider applicability by considering more localized anomalies and by the inclusion of advective transport processes.

The modification of the response by sea ice changes and the absence of any statistically significant change in the basin-averaged hydrological cycle are also discussed.
\end{abstract}

\section{Introduction}

The response of three-dimensional ocean models under highly idealized upper boundary conditions (BCs) to high-latitude freshening includes a general cooling in the region, a collapse of the meridional overturning, and a freshening far beyond that due to the original perturbation. This so-called "polar halocline catastrophe" (Bryan 1986) is associated with feedback mechanisms that depend upon the $\mathrm{BC}$ on temperature (e.g., Power and Kleeman 1993, 1994; Zhang et al. 1993; Power et al. 1994; Rahmstorf and Willebrand 1995). This BC can be expressed as

$$
Q(1)=Q^{*}-\kappa\left(T(1)-T^{*}\right),
$$

where $Q(1)$ is the net surface heat flux out of the upper level of the ocean model, $Q^{*}$ is a fixed background value, $\kappa=-\left(Q(1)-Q^{*}\right) /\left(T(1)-T^{*}\right)=-\Delta Q / \Delta T$ is a heat flux response coefficient, $T(1)$ is the upperlevel temperature of the model, and $T^{*}$ is a reference temperature. If a negative value is assigned to $\kappa$ (as is

Corresponding author address: Dr. S. B. Power, Bureau of Meteorology Research Centre, GPO Box 1289K, Melbourne, Victoria 3001, Australia.

E-mail: sbp@bom.gov.au almost always the case), then $\Delta Q / \Delta T$ is positive and so deviations in $T(1)$ away from $T^{*}$ are dampened. If heat were then added to the upper ocean of the model from an additional source then this damping would tend to restore the upper-level temperature toward $T^{*}$, so it is commonly referred to as a restoring $\mathrm{BC}$. It is interesting to note, however, that when (1) is applied in conjunction with a fixed surface salt flux (a combination sometimes referred to as "mixed BCs"), it can have a destabilizing influence on the climatology of the model (Power and Kleeman 1993, 1994; Zhang et al. 1993; Power et al. 1994; Rahmstorf and Willebrand 1995; Power 1995). In fact, if weaker restoration is employed (i.e., $|\kappa|$ is reduced, $\kappa<0$ ), ocean models under mixed BCs become increasingly less sensitive to freshening at high latitudes, to the point where no collapse occurs for even very large initial perturbations. This is significant because the application of the restoring condition in the context of climate change is uncertain (e.g., Power and Kleeman 1993, 1994; Zhang et al. 1993; Gildor et al. 1994; Mikolajewicz and MaierReimer 1994; Power et al. 1994; Rahmstorf and Willebrand 1995). For example, Bretherton (1982), Schopf (1983), Frankignoul (1985), Zhang et al. (1993), Kleeman and Power (1995), and Rahmstorf and Willebrand (1995) have presented evidence show- 
a

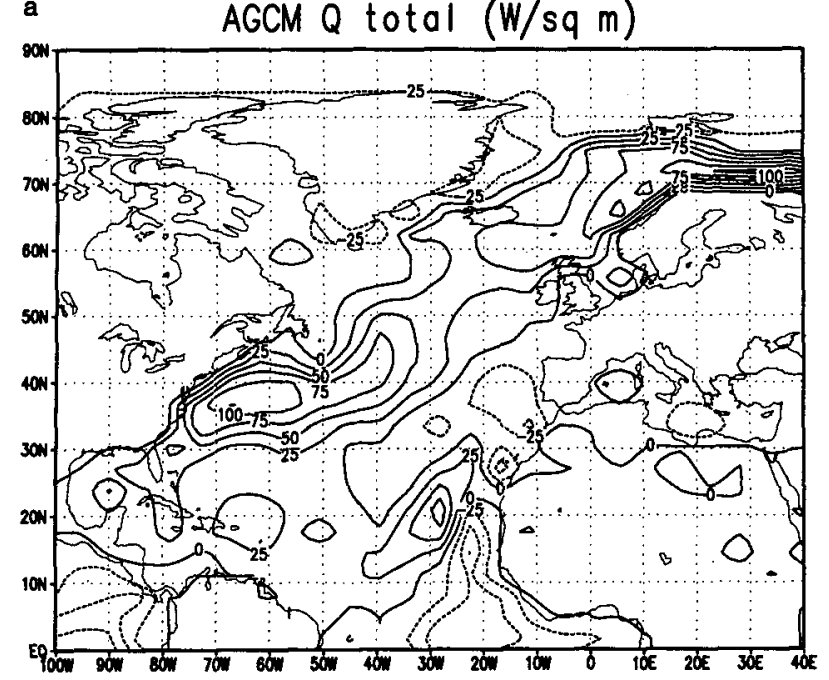

c

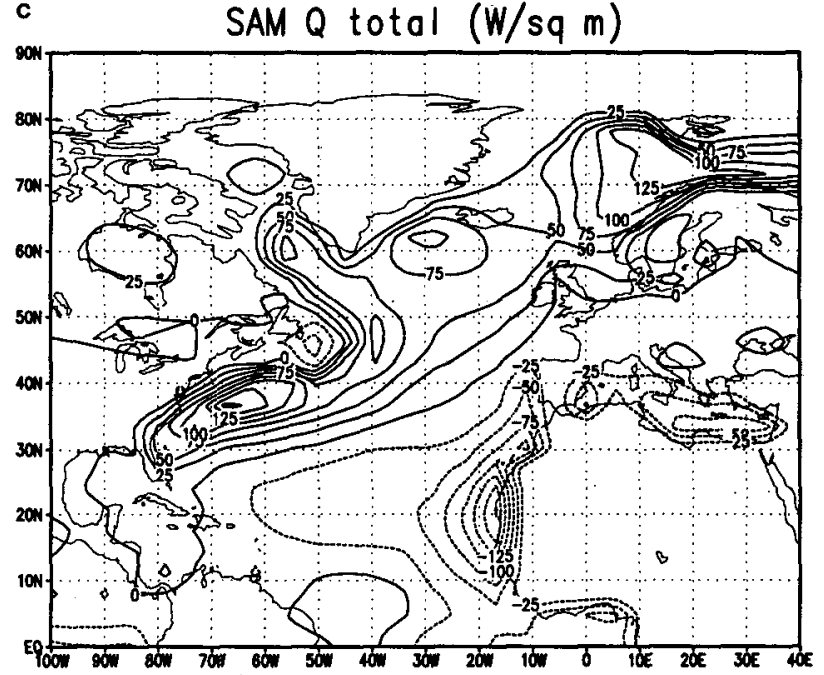

b Obs $Q$ total (W/sq m)

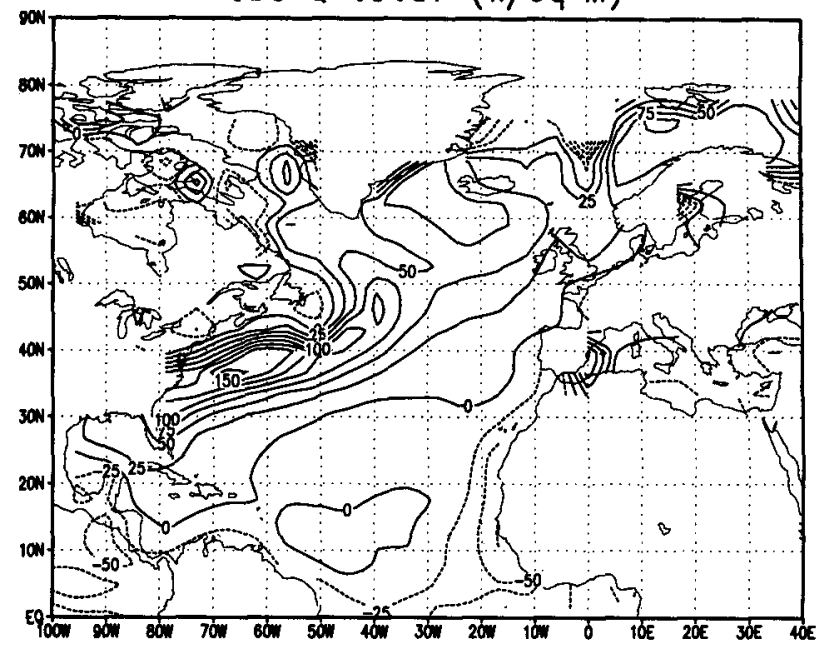

Fig. 1. The total surface heat flux $(Q)$ over the North Atlantic calculated by (a) the AGCM, (b) Oberhuber (1988) using the Comprehensive Ocean Atmosphere Data Set (Woodruff et al. 1987), and (c) the Simple Atmospheric Model (SAM). The contour interval is $25 \mathrm{~W} \mathrm{~m}^{-2}$ in all plots; $Q$ is positive out of the ocean.

ing that the rate at which anomalies are damped is very much a function of its horizontal extent-the greater the extent the weaker the restoration. This is because the underlying atmospheric processes, which lead to the decay of the SST anomaly and the timescales associated with these processes, are also scale dependent: heat loss by longwave emission to space is believed to dominate the ultimate erosion of global-scale anomalies, whereas advective transport processes act to erode smaller-scale anomalies.

Additional uncertainty regarding the restoring $\mathrm{BC}$ arises because the bulk of SST anomalies at midlatitudes are believed to be forced by heat flux anomalies, which arise from atmospheric changes on daily, monthly, and even interannual timescales (Namias and Cayan 1981; Frankignoul 1985; Cayan 1990, 1992), so it is not clear how appropriate a restorative heat flux response to midlatitude SST anomalies is on climatic timescales.
Various studies (Ratcliffe and Murray 1970; Palmer and Sun 1985; Frankignoul 1985; Rind et al. 1986; Lau and Nath 1990; Kushnir and Lau 1992; Deser and Blackmon 1993; Peng and Mysak 1993; Kushnir 1994) have discussed the atmospheric response to midlatitude SST anomalies. These studies have emphasized the role played by baroclinic disturbances and storm track shifts in determining the average response, the potential for the response to depend nonlinearly on the sign of the anomaly, and the relocation of midlatitude rain belts. Rind et al. (1986) determined the response of a coarse AGCM (atmospheric general circulation model ) to a large and extensive SST anomaly in the North Atlantic. This anomaly was based upon a CLIMAP (1981) reconstruction of the Younger Dryas cooling (11-10 000 years BP). They found that the anomaly forced a reduction in evaporation, and that this led to a reduced net heat flux out of the ocean. Judging by their plots of SST anomaly $(\Delta T)$ and total 


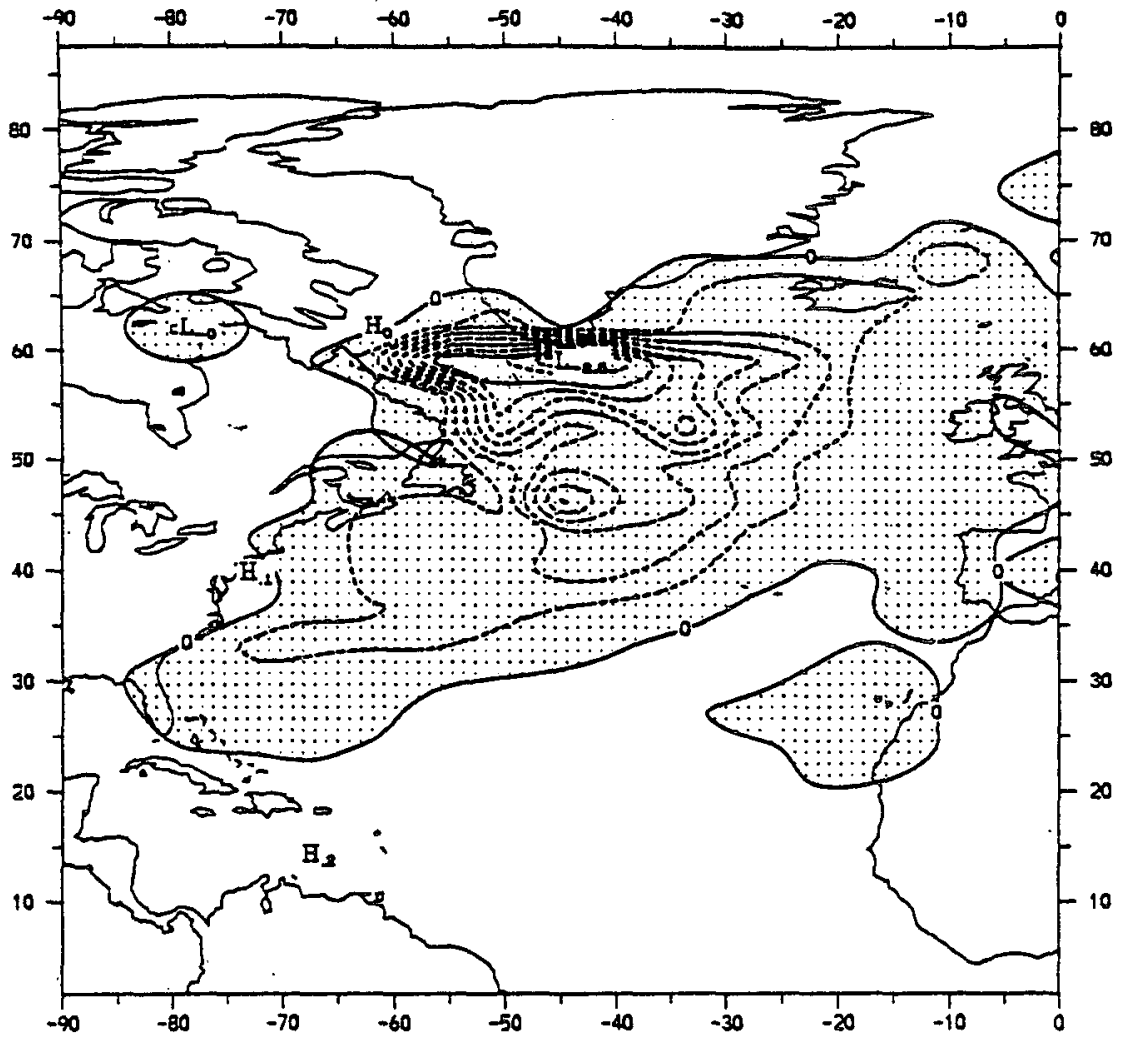

FIG. 2. The SST anomaly obtained by Power and Kleeman (1994) that is used in most of the experiments described here. Contour interval: $0.2^{\circ} \mathrm{C}$.

heat flux response $(\Delta Q)$, the response coefficient was around $-10 \mathrm{~W} \mathrm{~m}^{-2}{ }^{\circ} \mathrm{C}^{-1}$ (and therefore restorative) but exhibited a good deal of spatial variation. This is consistent with the results obtained by Lau and Nath (1990), which showed that the fluctuations in the combined latent and sensible heat flux were typically -20 to $-10 \mathrm{~W} \mathrm{~m}^{-2}{ }^{\circ} \mathrm{C}^{-1}$ in their 30 -year integration of an AGCM. Frankignoul (1985) summarized additional work, which highlighted the importance of air temperature changes in reducing the heat flux response. The heat flux response in the studies Frankignoul discussed provided a negative feedback on the original SST anomaly with $\kappa$ typically $-20 \mathrm{~W} \mathrm{~m}^{-2}{ }^{\circ} \mathrm{C}^{-1}$, although the precise response differed from one model to another (in fact no simple relationship between SST and heat flux seemed to exist in one of the integrations discussed). Frankignoul (1985) also mentioned the ability of the atmosphere to help move midlatitude SST anomalies farther east via atmospheric advection.

Here we will force two atmospheric models using SST anomalies derived from an ocean model in which the production of North Atlantic Deep Water is subdued. If the values of $\kappa$ in the response indicate that the restoring $\mathrm{BC}$ is valid and the magnitude is similar to that employed in the earlier ocean modeling studies, then we can have more faith in their assessment of climatic stability.
Both an AGCM and a simple heat flux response model (Kleeman and Power 1995) will be used to determine the response to the SST changes. Simple analytic models, similar to that described by Schopf (1985), will be used to help interpret some of the salient features of the response evident in the more sophisticated models. The simpler models provide a convenient framework in which most of the mechanisms that underlie the response can be studied and understood. They will also be used to briefly explore the impact of sea ice changes, consistent with the imposed SST changes.

While the emphasis here is on the heat flux response, the AGCM freshwater flux response (the change in $R$ $+P-E$, where $R$ is the runoff, $P$ the precipitation, and $E$ the evaporation ) is also determined in an attempt to see if the reduced temperatures produce an increase in the freshwater delivered to the North Atlantic. The importance of this feedback remains uncertain as some studies point to only a small modifying role (e.g., Wang and Birchfield 1992; Power et al. 1994), whereas others (Rind et al. 1986; Duplessy et al. 1992; Nakamura et al. 1994) suggest a destabilizing role of fundamental importance: cooled surface temperatures are associated with an increase in $P-E$. In a coupled atmosphereocean model this would serve to diminish both the overturning and, because of a reduction in the north- 

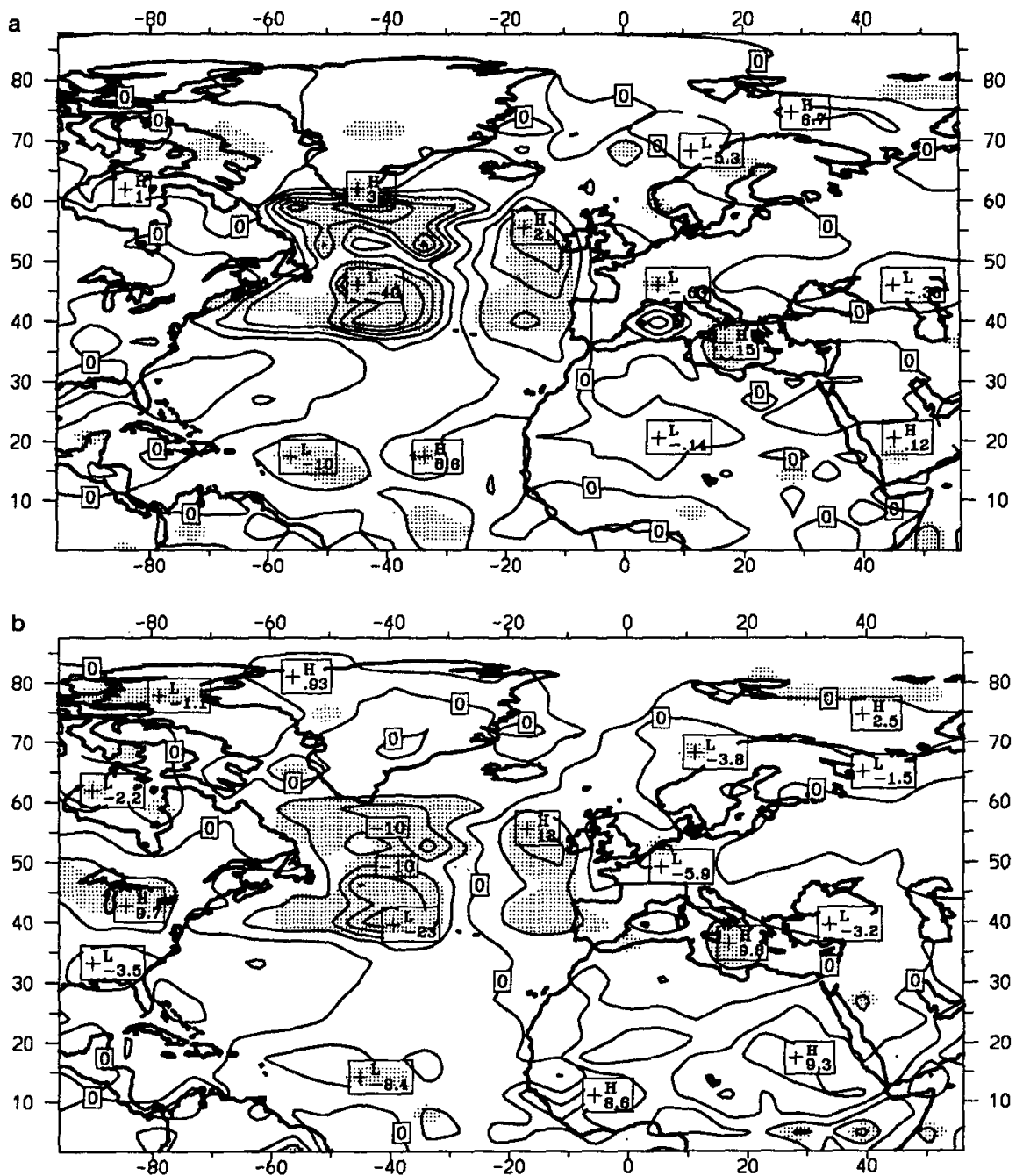

FIG. 3. The AGCM heat flux response to the SST anomaly depicted in Fig. 2: (a) total, (b) latent, (c) sensible, (d) net surface radiation, and (e) $\kappa=-\Delta Q / \Delta S S T$. Units: $\mathrm{W} \mathrm{m}^{-2}$ for (a)-(d) and $\mathrm{W} \mathrm{m}^{-2}$ ${ }^{\circ} \mathrm{C}^{-1}$ for (e). Shading in (a)-(d) indicates that the change is significant at the $95 \%$ level. Negative values indicate that the SST anomaly is damped.

ward advection of relatively warm water, the surface temperatures even further.

The atmospheric models and the derivation of the SST anomalies used to perturb their climatologies are described in more detail in the following section. The results are presented in section 3 and are summarized and briefly discussed in section 4 .

\section{The atmospheric models and the SST anomaly \\ a. The $A G C M$}

Most features of the AGCM have been described by Bourke et al. (1977), McAvaney et al. (1978, 1991), Bourke (1987), Hart et al. (1988, 1990), McAvaney and Colman (1993), and Power et al. (1993). The equations are solved using a spectral transform technique (Bourke et al. 1977) with rhomboidal truncation at wavenumber 21 . Sigma coordinates are used in the vertical with nine unequally spaced levels.

Both the boundary layer and the vertical diffusion parameterizations are similar to those given by Louis (1982). Penetrative convection is treated by a mass flux scheme (Tiedtke 1989), and shallow convection is the same as that described by Tiedtke (1984). Evaporation over the oceans is enhanced by employing a modified exchange coefficient at low wind speeds (Miller et al. 1992). Gravity wave drag is determined using the formulation of Palmer et al. (1986), while radiation is treated using a modified version of the Fels and Schwarzkopf (1975) scheme. The diagnostic cloud scheme calculates cloud fractions in three distinct layers, and the cloud fraction is evaluated in each of these layers from the relative humidity via simple formulas. 

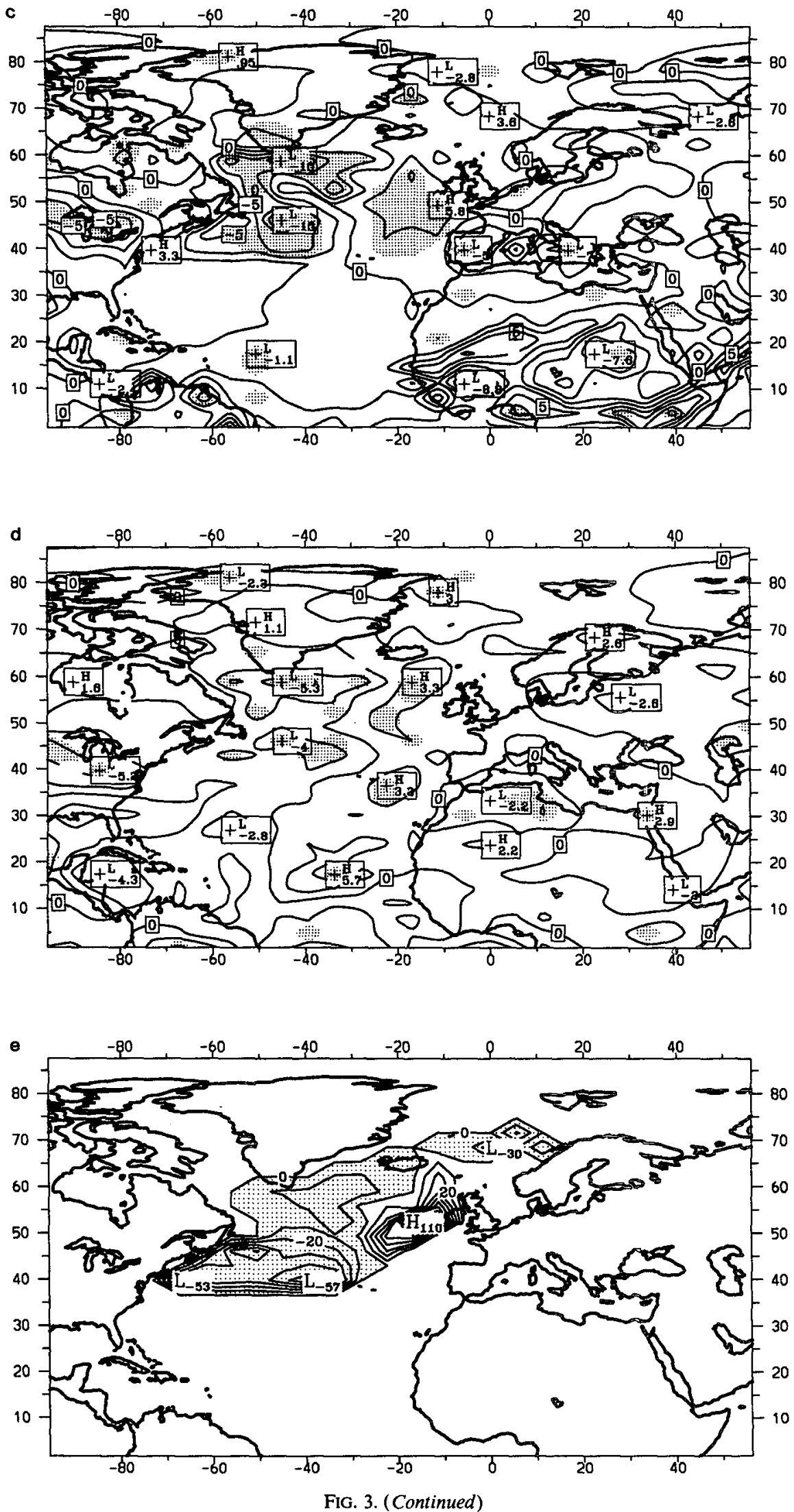
The control simulation was integrated for a total of 7.5 years with both diurnal and seasonal forcing. The first 6 months were discarded to allow the model to equilibrate. Some of the strengths and weaknesses of the simulation have been discussed by Power et al. (1993). The total heat flux from the AGCM and observations (Oberhuber 1988) are presented in Figs. 1a and $1 \mathrm{~b}$, respectively. There is generally good agreement between these fields. In particular, both show large upward fluxes extending from Florida northeastward across the North Atlantic, although the AGCM appears to underestimate values over the Gulf Stream. Over Davis Strait to the southwest of Greenland, the model upward flux is low compared with the observational estimate, which is primarily due to lower latent heat fluxes. West of Africa the AGCM heat flux out of the ocean is greater than the observational estimate. This is due to a large local latent heat flux and low values of the downward SWR (shortwave radiation) associated with cloud distribution in the AGCM.

\section{b. The simple atmospheric model}

Until quite recently, ocean modelers have employed restoring formulae like Eq. (1) in studies dealing with climatic stability. The simple atmospheric model (SAM) of surface heat flux used here represents an attempt to provide a more realistic response while avoiding the computational cost of a full AGCM. SAM has been described in detail by Kleeman and Power (1995). It consists of a single layer, which models the atmospheric layer in turbulent contact with the underlying surface. This includes the boundary layer as well as a portion of the cloud layer. The surface fluxes of both latent and sensible heat over the ocean are calculated using bulk formulae:
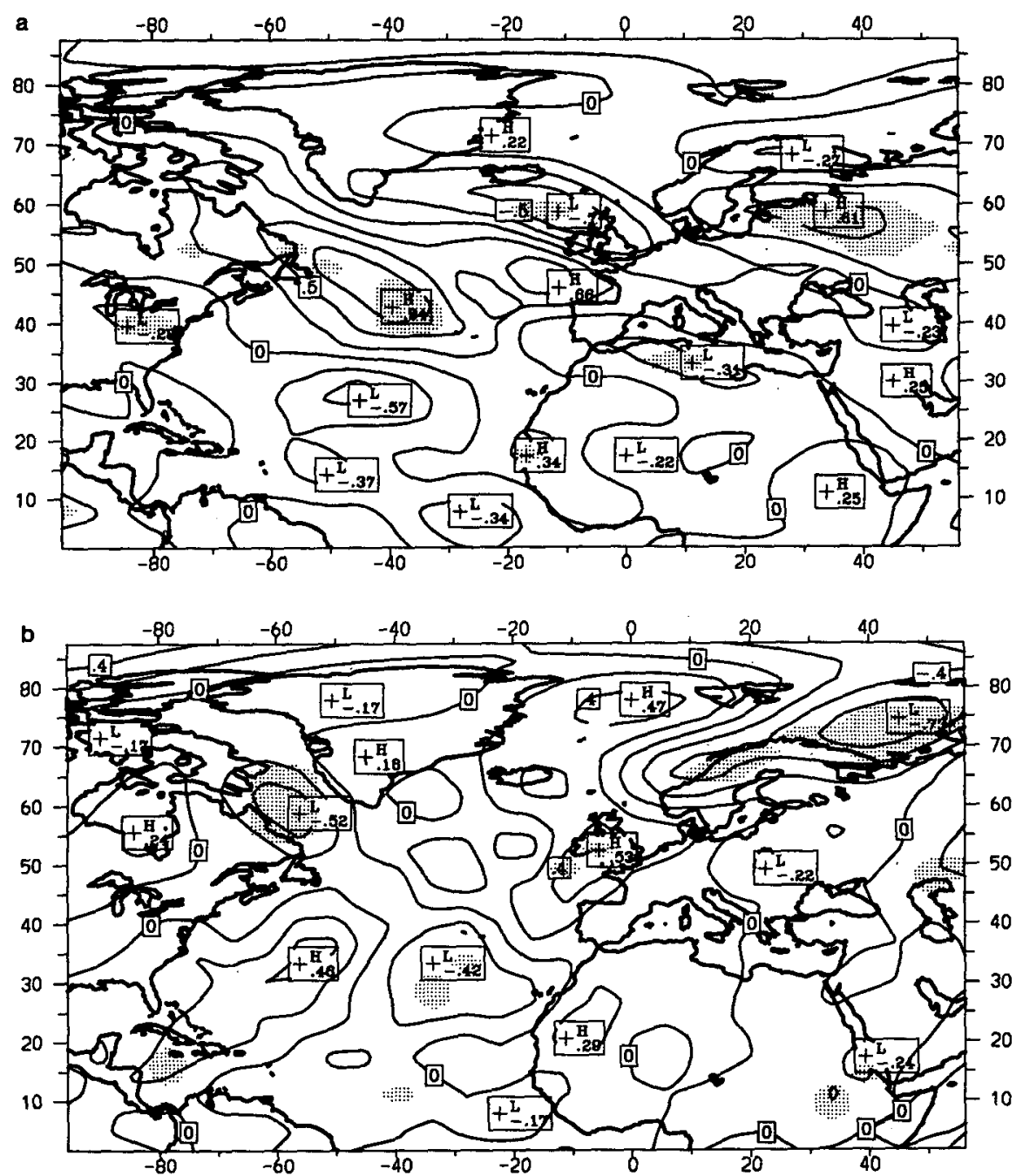

FIG. 4. Change in the AGCM (a) zonal and (b) meridional wind at the lowest sigma level in meters per second. 


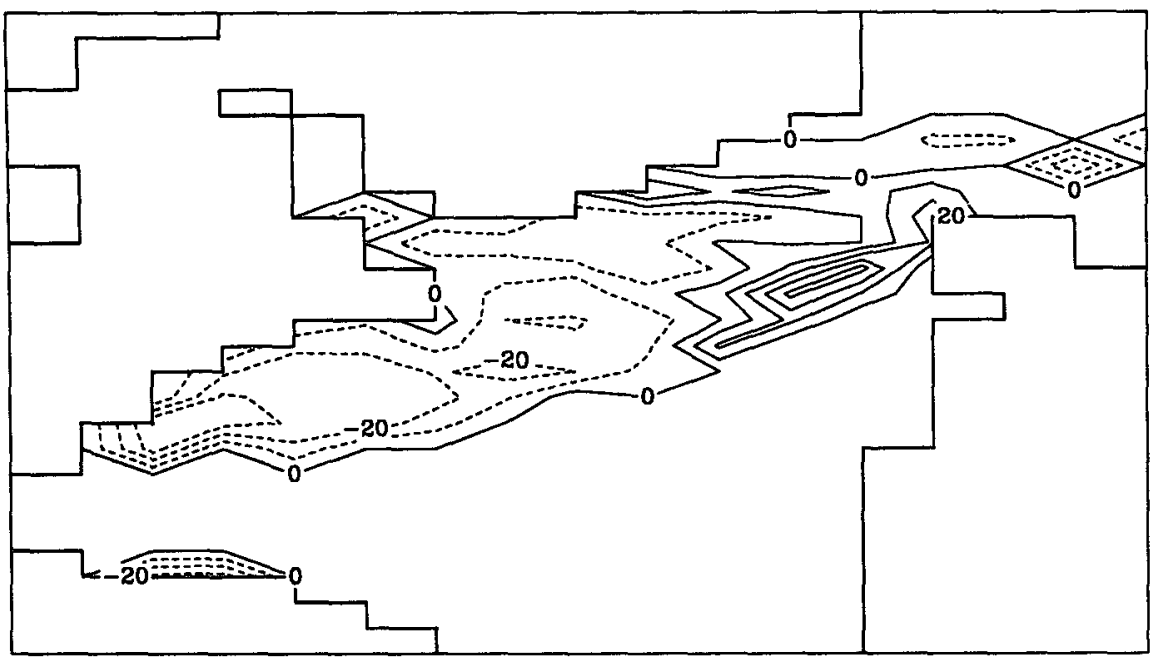

FlG. 5. Response of SAM to the SST anomaly depicted in Fig. 2, as measured by $\kappa=-\Delta Q / \Delta S S T$. Units: $\mathrm{W} \mathrm{m}^{-2}{ }^{\circ} \mathrm{C}^{-1}$.

$$
\begin{gathered}
Q_{\text {lat }}=\rho_{a} W c_{E} L_{v}\left(q_{\mathrm{sat}}\left(T_{s}\right)-\mathrm{RH} q_{\mathrm{sat}}\left(T_{a}\right)\right) \\
Q_{\mathrm{sens}}=\rho_{a} W c_{p} c_{H}\left(T_{s}-T_{a}\right),
\end{gathered}
$$

where $T_{s}$ is the surface temperature, $T_{a}$ is the atmospheric temperature near the surface, $W$ is the mean climatological surface wind speed, $c_{H}$ and $c_{E}$ are the usual dimensionless turbulent exchange coefficients, $q_{\text {sat }}\left(T_{a}\right)$ is the saturation specific humidity at temperature $T_{a}, \rho_{a}$ is the density of the air, $c_{p}$ is its specific heat, $L_{v}$ the latent heat of vaporization, and $\mathrm{RH}$ the relative humidity. The temperature tendency equation for the atmospheric layer includes the effects of (a) horizontal and (b) vertical advection; (c) horizontal diffusion by transient eddies; and (d) turbulent, stability-dependent sensible heat exchange with the sur-

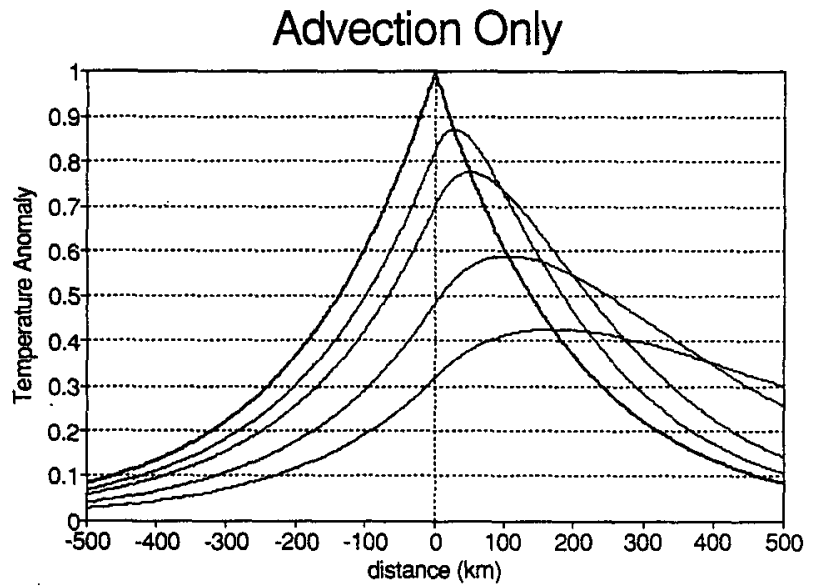

FIG. 6. Analytic solution to $u T_{x}=r\left(T^{*}-T\right)$ for $T^{*}=T e^{-\mu|x|}$ with $1 / \mu=200 \mathrm{~km}, r=2^{\circ} \mathrm{C}_{\text {day }}{ }^{-1}$, and $u=1,2,5$, and $10 \mathrm{~m} \mathrm{~s}^{-1}$. The solution is displaced farther to the right, away from the imposed SST (heavy, sharp pointed curve). face. The net longwave radiation (LWR) and the (constant) net SWR are based on an empirical formula given by Gill (1982). Surface temperatures over land and sea-ice are determined prognostically. The model is implemented on an R21 global spectral grid, and provides a relatively inexpensive estimate of the surface heat flux response to SST anomalies that are not dominated by changes in the low-level atmospheric circulation, cloudiness, upper-air temperature, or land albedo, since all of these things are fixed.

The surface heat flux in the control integration of this model is presented in Fig. Ic and has been discussed by Kleeman and Power (1995). The model captures the qualitative and, to a reasonable extent, the quantitative aspects of the observational estimate of the heat flux over most areas, including the Gulf Stream and

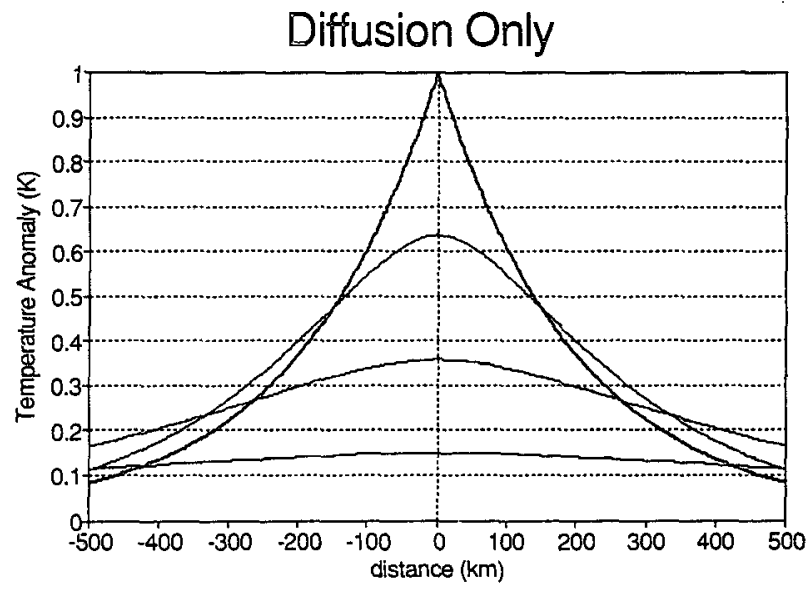

FiG. 7. Analytic solution to $r\left(T^{*}-T\right)+\nu T_{x x}=0$ for $T^{*}=T e^{-\mu|x|}$ with $1 / \mu=200 \mathrm{~km}, r=2^{\circ} \mathrm{C} \mathrm{day}^{-1}$, and $\nu=0.3,1.0,3.0$, and 10.00 $\times 10^{6} \mathrm{~m}^{2} \mathrm{~s}^{-1}$. The solution becomes more homogeneous as $\nu$ increases. 


\section{Advection \& Diffusion}

$\mathrm{K}=1 \mathrm{e}+6 ; \mathrm{u}=0,5$ \& 10

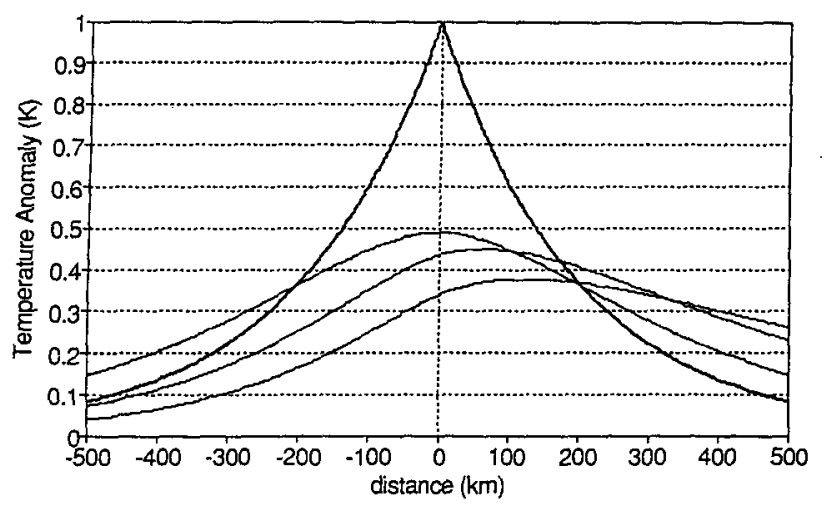

FIG. 8. Analytic solution to $u T_{x}=r\left(T^{*}-T\right)+\nu T_{x x}$, for $T^{*}$ $=T e^{-\mu|x|}$, with $1 / \mu=200 \mathrm{~km}, r=2^{\circ} \mathrm{C} \mathrm{day}^{-1}$, and $\nu=1.0 \times 10^{6}$ $\mathrm{m}^{2} \mathrm{~s}^{-1}$, and $u=0,5$, and $10 \mathrm{~m} \mathrm{~s}^{-1}$. The solution is again displaced farther to the right as $u$ increases.

the Barents Sea. The major deficiencies between them occur over Davis Strait and off the western coast of North Africa. The latter is probably due to the assumption of fixed relative humidity, which causes an underestimate of evaporation in the dry air region (Kleeman and Power 1995). The Davis Strait difference is due to a large sensible heat flux associated with the eddy transport of cold air off adjacent land masses. A reviewer suggests that it might also be associated with the neglect of boundary layer growth in the model.

We will see in the following section that the simple model provides a heat flux response that is similar to that given by the AGCM in most but not all respects. Both the similarities and the differences will be discussed.

\section{c. The OGCM and the SST anomaly field}

An OGCM (oceanic GCM) was previously used by Power and Kleeman (1994) to obtain two equilibrium states under the same mixed BCs. The OGCM they employed is a recent version of the Geophysical Fluid Dynamics Laboratory code (Pacanowski et al. 1991), which is based on the work of Bryan (1969), Bryan and Lewis (1979), and Cox (1984) and is given the acronym MOM (modular ocean model). The model solves the primitive equations of motion obtained when the Boussinesq, rigid-lid, and hydrostatic approximations have been made. The model has a resolution of approximately 3.2 by 5.6 degrees in the horizontal and 12 unequally spaced vertical levels.

The SST anomaly used here (Fig. 2) was obtained by conducting the following experiments. First, a solution was obtained by restoring the upper-level temperature and salinity to annually averaged observational estimates of the sea surface temperature and salinity (Levitus 1982) on a timescale of 20 days. This

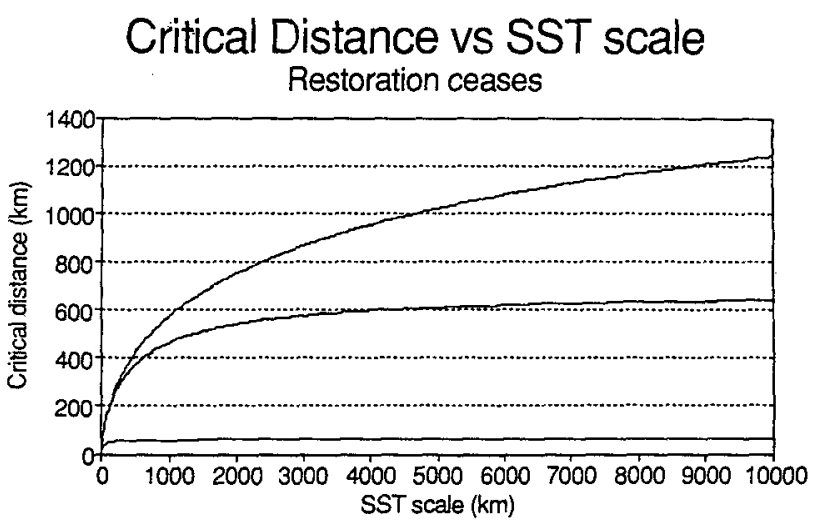

FIG. 9. Analytic solution for $x$ crit as a function of $1 / \mu$ for 3 cases: (i) $\nu=3.0 \times 10^{3} \mathrm{~m}^{2} \mathrm{~s}^{-1}, u=2 \mathrm{~m} \mathrm{~s}^{-1}$ (lower curve); (ii) $\nu=3.0 \times 10^{6}$ $\mathrm{m}^{2} \mathrm{~s}^{-1}, u=2 \mathrm{~m} \mathrm{~s}^{-1}$ (middle curve); and (iii) $\nu=3.0 \times 10^{6} \mathrm{~m}^{2} \mathrm{~s}^{-1}, u$ $=0 \mathrm{~m} \mathrm{~s}^{-1}$ (upper curve).

is equivalent to employing a heat flux response coefficient of approximately $-60 \mathrm{~W} \mathrm{~m}^{-2}{ }^{\circ} \mathrm{C}^{-1}$, which falls within the range employed in a number of studies using ocean models under mixed BCs $(-80$ to -40 $\mathrm{W} \mathrm{m} \mathrm{m}^{-2}{ }^{\circ} \mathrm{C}^{-1}$ ). Observational estimates of the annually averaged wind stress (Hellerman and Rosenstein 1983) were also applied. After a quasi-equilibrium solution was obtained, the surface flux of salt was then diagnosed from a 50 year run. Then mixed BCs were applied so that the restoration was maintained on $T$ but the salt flux was fixed to its diagnosed value. The model was then integrated in this way to obtain solution $M_{1}$. A freshwater flux anomaly was then applied to the North Atlantic for a short period and then subsequently integrated to obtain a further equilibrium solution $M_{2}$. This solution has a substantially weakened overturning in the North Atlantic, which results in a cooling over the North Atlantic. The difference between the SST in $M_{1}$ and in $M_{2}$ [which is greater than or equal to ap-

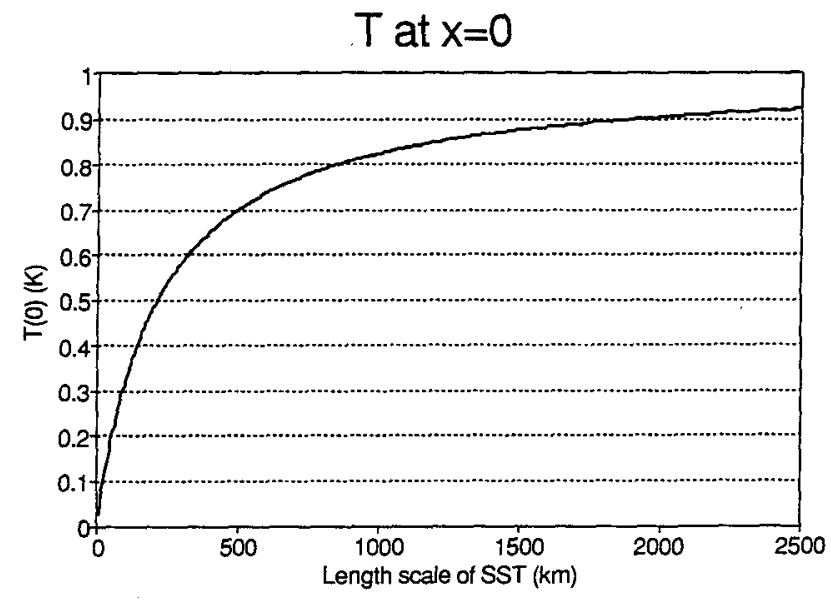

FIG. 10. Analytic solution for $T$ at $x=0$ as a function of $1 / \mu$ for the cases $\nu=2.0 \times 10^{6} \mathrm{~m}^{2} \mathrm{~s}^{-1}$ and $u=2 \mathrm{~m} \mathrm{~s}^{-1}$. 
proximately $-2.2^{\circ} \mathrm{C}$ at all sites (see Fig. 2)] is used to perturb the atmospheric models to determine their heat flux response. These responses will then be compared with each other and with the heat flux anomaly diagnosed from the OGCM under mixed BCs.

\section{Results}

\section{a. Heat flux feedback}

The AGCM was again integrated for 7.5 years with the SST anomaly imposed throughout the entire run. The first 6 months were again discarded. This perturbed solution was then compared with the control run described in section $3 \mathrm{a}$. The heat flux response $\Delta Q$ and its various components are presented in Fig. 3. The shading indicates that the change is statistically significant at the 95\% level using a standard $t$ test in which neither the population mean nor the variance are known a priori (Walpole and Myers 1990, Table 8.2, case 5 ). The response is generally restorative (Fig. 3a) with the bulk of the heat anomaly into the ocean over the anomaly. There is, however, a component to the response that would enhance the surface temperature anomaly over its eastern flank.

Recall that the local response can be measured by the heat flux response coefficient, $\kappa=-\Delta Q / \Delta \mathrm{SST}$, and that the sign of $\kappa$ gives the sign of the feedback; $\kappa$ is plotted in Fig. 3e, wherever $\Delta S S T$ exceeds $0.125^{\circ} \mathrm{C}$. It exhibits a great deal of spatial variability but is typically -20 to $-10 \mathrm{~W} \mathrm{~m}^{-2}{ }^{\circ} \mathrm{C}^{-1}$ over the main body of the SST anomaly. This is outside the range used in the earlier ocean modeling studies described earlier. Consequently, a much greater salinity anomaly would probably have been required to force the collapse evident in $M_{2}$ (Power and Kleeman 1994). The positive values toward the east indicate that the restoring condition can misrepresent the nature of the heat flux feedback.

The various changes in latent heat flux, sensible heat flux, and net surface radiation (Figs. $3 b-d$ ) are all qualitatively similar in structure over the North Atlantic: the most extreme negative values occur over the southern part of the anomaly over the warmer water. The largest positive values are found to the east, extending beyond the SST anomaly. The response is dominated by latent heating. Sensible heating is the second most important term, while radiation plays the smallest role. The large local response occurs because the air advected into the region is largely unchanged, so it is anomalously warm relative to the ocean. Thus, both latent and sensible heat fluxes out of the ocean are generally reduced. This simple picture is complicated because the air adjusts as it passes over the anomaly and the winds have been modified in both speed and direction in a spatially dependent fashion. This is illustrated in Fig. 4, which depicts the relatively modest change in the wind at the lowest sigma level. The westerlies around $45^{\circ} \mathrm{N}$ and the easterlies around $60^{\circ} \mathrm{N}$ have weakened over the western and central North Atlantic (Fig. 4a). The northerlies south of Greenland have weakened, while the southerlies near $40^{\circ} \mathrm{N}, 40^{\circ} \mathrm{W}$ have strengthened (Fig. $4 \mathrm{~b}$ ).

SAM's response to the same SST anomaly is also generally restorative, with $\kappa$ around $-20 \mathrm{~W} \mathrm{~m}^{-2}{ }^{\circ} \mathrm{C}^{-1}$ in Fig. 5, although the reinforcement and eastern enhancement is also evident. This enhancement occurs in both models because the air is cooled as it passes over the bulk of the anomaly in the west, to the extent that the air-sea temperature difference has actually increased toward the east (not shown).

To illustrate this, consider a simple, steady, 1D model, which contains some of the dominant thermodynamical processes evident in SAM, namely

$$
u T_{x}=r\left(T^{*}-T\right)+\nu T_{x x},
$$

where $T$ is now the air temperature, $T^{*}$ the imposed surface temperature, $u$ the wind speed, $r$ determines the sensible surface heating rate for a given air-sea temperature difference, $T^{*}-T$, and the subscript $x$ refers to spatial differentiation. The solution is given by

$$
T(x)=r \underline{T} /(2 \gamma \nu)\left\{\begin{array}{l}
H_{m} e^{(\theta+\gamma) x}+G_{m} e^{\mu x}, x<0 \\
H_{p} e^{(\theta-\gamma) x}+G_{p} e^{-\mu x}, x \geqslant 0,
\end{array}\right.
$$

where $G_{m}=1 /(\gamma+\theta-\mu)+1 /(\gamma+\mu-\theta), G_{p}=1 /$ $(\gamma+\theta+\mu)+1 /(\gamma-\mu-\theta), H_{p}=-\left[G_{p}(\mu+\gamma\right.$ $\left.+\theta)+G_{m}(\mu-\gamma-\theta)\right] /(2 \gamma)$, and $H_{m}=G_{p}-G_{m}$ $+H_{p}$ if the imposed SST anomaly takes the form $T^{*}=T e^{-\mu|x|}$. Here $\gamma^{2}=\left(u^{2} / 2 \nu^{2}+r / \nu\right)$ and $\theta$ $=u / 2 \nu$. If $\nu=0$ then (3) reduces to

$$
T(x)=\underline{T}\left\{\begin{array}{c}
e^{\mu x} /(1+u \mu / r), \quad x<0 \\
e^{-\mu x} /(1-u \mu / r)-2(u \mu / r) e^{-r x / u} / \\
{\left[1-(u \mu / r)^{2}\right], \quad x \geqslant 0}
\end{array}\right.
$$

This advective solution is presented in Fig. 6 for the cases $u=1,2,5$, and $10 \mathrm{~m} \mathrm{~s}^{-1}$, with $1 / \mu=200 \mathrm{~km}$ and $r=2^{\circ} \mathrm{C} \mathrm{day}^{-1}$. The solution is restorative upwind (with $T<T^{*}$ so that surface heating would tend to erode the SST anomaly) and has a magnitude that increases with $u$. The response remains restorative through $x=0$ to a position $x_{\text {crit }}>0$, which increases as $u$ increases. This switch in behavior occurs where $T^{*}-T=0$, or $\left.x=\ln [(r / \mu u)+1) / 2\right] /(\mu-r / u)$. This quantity is positive only if $1 / \mu<u / r$. Here $1 / \mu$ provides a length scale for the SST anomaly, and $u / r$ is the length scale an air temperature anomaly will be advected before it is damped by the surface flux. For a nonrestorative feedback to arise, the second scale must exceed the first so that the air temperature signal advected from the main SST anomaly center persists far enough away from the center to actually dominate the surface flux. The downstream surface forcing away from the SST anomaly is due to the same mechanism. 

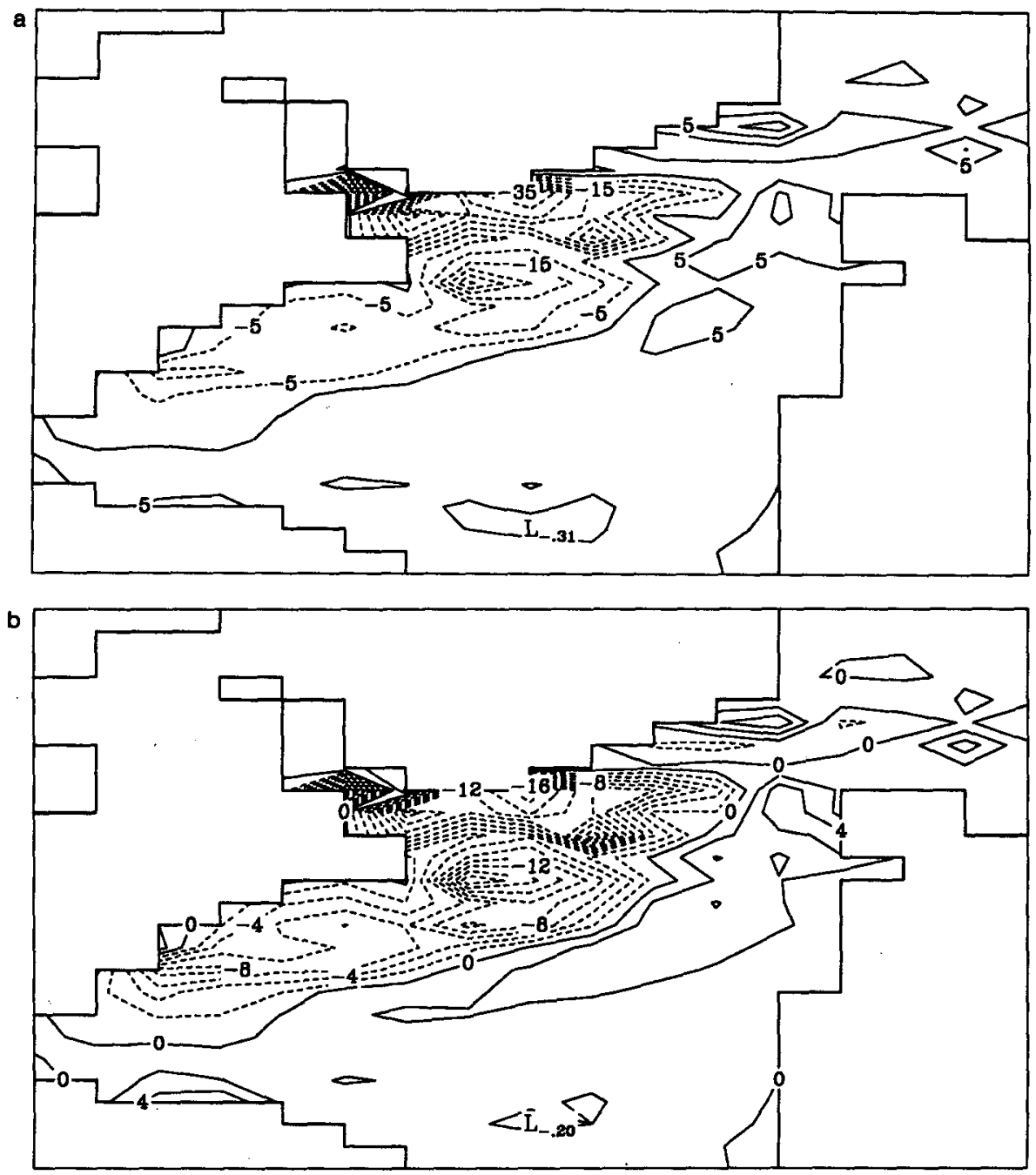

FIG. 11. The heat flux response in SAM to the standard SST anomaly: (a) total, (b) latent, (c) sensible, and (d) net LWR. Units: $\mathrm{W} \mathrm{m}^{-2}$.

This is illustrated by solving (2), but this time with the SST anomaly restricted to a finite region:

$$
T^{*}= \begin{cases}\underline{T}, & 0 \leqslant x \leqslant L \\ 0, & \text { otherwise }\end{cases}
$$

In this case the air temperature is given by

$$
T(x)=\underline{T} \begin{aligned}
& 0, \quad x<0 \\
& \left(1-e^{-r x / u}\right) ; \quad 0 \leqslant x \leqslant L \\
& \left(e^{r L / u}-1\right) e^{-r x / u}, \quad x>L,
\end{aligned}
$$

so the downwind response away from the anomaly decays with scale $u / r$ and has an amplitude of $\underline{T}(1$ $\left.-e^{-r L / u}\right)$. It is interesting to note that in this case the heat flux feedback is everywhere restorative over the surface temperature anomaly. In this reduced model the SST anomaly must have spatial structure (i.e., $d /$ $d x \neq 0$ ) for a portion of the nonzero SST anomaly to be amplified.
The purely diffusive solution of (2) (i.e., with $u$ $=0$ ) is given by

$$
T(x)=\gamma \underline{T} / 2\left\{\begin{array}{l}
H e^{\gamma x}+G e^{\mu x}, \quad x<0 \\
H e^{-\gamma x}+G e^{-\mu x}, \quad x \geqslant 0,
\end{array}\right.
$$

where $G=1 /(\gamma+\mu)+1 /(\gamma-\mu)$ and $H=-\mu G$. The solution is presented in Fig. 7 for the cases $\nu$ $=0.3,1.0,3.0$, and $10.0\left(\times 10^{6} \mathrm{~m}^{2} \mathrm{~s}^{-1}\right)$. These values fall in the range given by Gill $(1982$, p. 591$)$ and are comparable with the value used in SAM $\left(3 \times 10^{6}\right.$ $\left.\mathrm{m}^{2} \mathrm{~s}^{-1}\right)$. The solution is symmetric, maximum restoration occurs at the origin and increases in magnitude as $\nu$ increases. The solution is no longer restorative beyond $x_{\text {crit }}$, (i.e., the position at which the air temperature is the same as the underlying imposed SST) which increases with $\nu$. This should be contrasted with the solution for a periodic surface temperature anomaly, which is always restorative and has a magnitude 

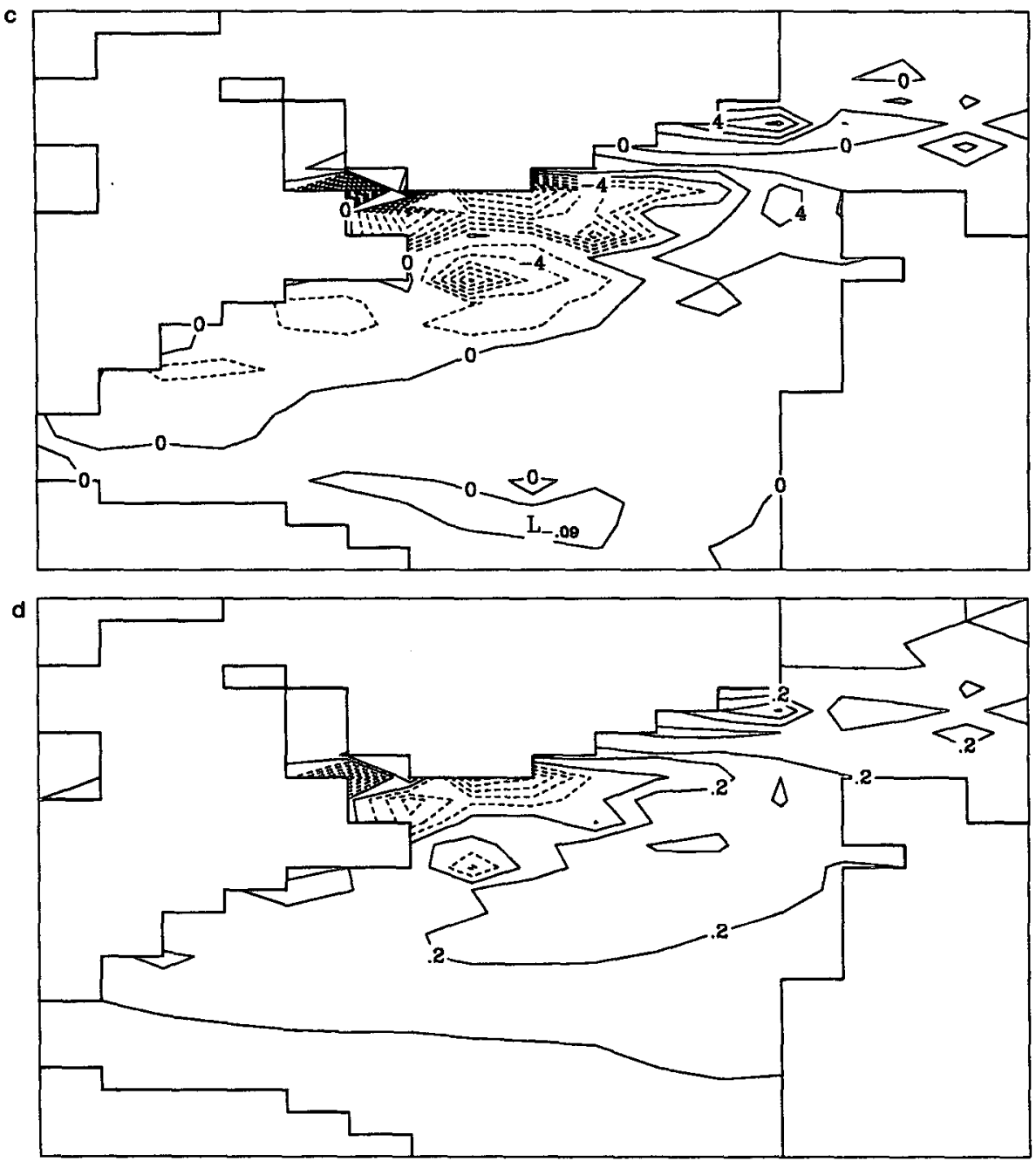

FIG. 11. (Continued)

proportional to $\gamma^{2} /\left(\gamma^{2}+k^{2}\right)$. Other properties of the solution in which the imposed surface temperature has a periodic spatial structure are described in the appendix.

Examples of solutions in which both advection and diffusion are important are presented in Fig. 8, where $\nu=1 \times 10^{6} \mathrm{~m}^{2} \mathrm{~s}^{-1}$ and $u=0,5$, and $10 \mathrm{~m} \mathrm{~s}^{-1}$. Restoration now occurs in an asymmetric band about $x$ $=0$. Having $u \neq 0$ creates an asymmetric solution, restoration is enhanced at $x=0$ as $u$ and $\nu$ increase and diffusion can make the upwind solution antirestorative. The solution downwind, well away from the anomaly peak, becomes increasingly antirestorative as $u$ increases. The distance $x_{\text {crit }}$ is plotted as a function of the SST length scale $1 / \mu$ in Fig. 9 for the case $\nu$ $=2 \times 10^{6} \mathrm{~m}^{2} \mathrm{~s}^{-1}$ and $u=2 \mathrm{~m} \mathrm{~s}^{-1}$. The critical distance increases rapidly for relatively small anomalies, but once the anomaly has a scale exceeding several hundred kilometers it increases much more slowly. The response is then better characterized as antirestorative. The de- pendence of the rate of restoration on the horizontal scale of the SST anomaly is illustrated in Fig. 10 in which $T$ at $x=0$ is depicted. The imposed surface temperature at $x=0$ is equal to unity. The rate of restoration is greatest for the smaller anomalies (where $T^{*}-T$ is a maximum), but decreases quite slowly once $1 / \mu$ exceeds about $1000 \mathrm{~km}$. If $1 / \mu$ is $100 \mathrm{~km}$, then SST - T at $x=0$ is about $0.25^{\circ} \mathrm{C}$, whereas if $1 /$ $\mu$ is $2500 \mathrm{~km}, T_{s}-T$ is about $0.9^{\circ} \mathrm{C}$. If we presume that the latent heating is proportional to the sensible heating, then the rate of restoration is nearly an order of magnitude greater for the smaller anomaly.

The various components of the heat flux response in SAM are depicted in Fig. 11, where we see that it is dominated by latent heating, followed by sensible heating, with only relatively minor radiative contributions. It is reassuring to note that this is the same hierarchy that we saw earlier in the AGCM response.

The changes in the tendencies due to eddy diffusion and advection in SAM are depicted in Fig. 12. 

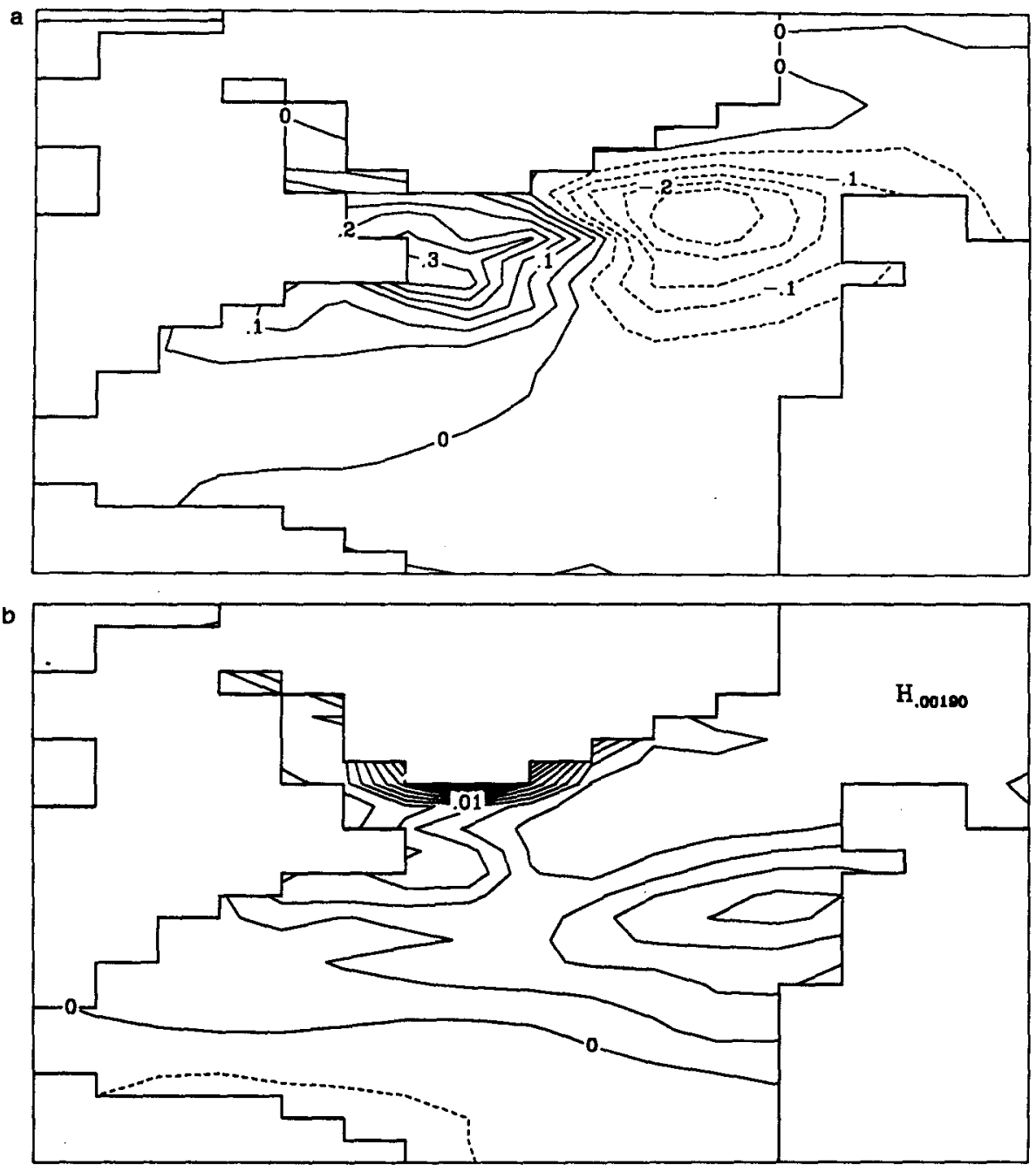

FIG. 12. The change in the (a) horizontal advection, (b) vertical advection, (c) eddy, and (d) sensible heating tendencies in response to the standard SST anomaly. The contour intervals are (a) 0.05 , (b) 0.002 , (c) 0.2 , and (d) $0.2^{\circ} \mathrm{C} \mathrm{day}^{-1}$.

The radiative cooling tendency is qualitatively similar to the sensible heating but an order of magnitude smaller, so it is not presented. As the eddy term parameterizes transient eddy (and subgrid scale) transports, it acts to smooth out the air temperatures in the region. The advection tendency exhibits two distinct regions: a positive region due to the advection of relatively warm air into the western flank of the anomaly and a broader negative region over the eastern flank extending over western Europe. In fact, this component of the tendency dominates the total downwind response. The sensible heating tendency has exactly the same structure as the sensible heat flux presented earlier. [The conversion factor is approximately $0.07^{\circ} \mathrm{C} \mathrm{day}^{-1}\left(\mathrm{~W} \mathrm{~m}^{-2}\right)^{-1}$.] The overall response is consistent with redistribution via primarily advective (diffusive) processes in the zonal (meridional) direction.

\section{$b$. Is the response linear?}

AGCM responses to midlatitude SST anomalies can be nonlinear (Ratcliffe and Murray 1970; Lau and Nath 1990; Kushnir and Lau 1992; Kushnir 1994). In order to see if the same is true here the anomaly was doubled in magnitude and reapplied. If the response were entirely linear, then $\kappa$ would be unchanged. The values of $k$ diagnosed from (a) the AGCM and (b) SAM are depicted in Fig. 13. These should be compared with Figs. 3e and 5, respectively. Generally speaking, $\kappa$ is similar in the AGCM, although magnitudes are somewhat reduced with the extremum lifted to $-37 \mathrm{~W} \mathrm{~m}^{-2}{ }^{\circ} \mathrm{C}^{-1}$ from its previous former of -57 $\mathrm{W} \mathrm{m} \mathrm{m}^{-2}{ }^{\circ} \mathrm{C}^{-1}$. The downwind enhancement also appears to be weaker. In SAM, however, $\kappa$ is much more stable. Evidently the processes that give rise to the nonlinear response evident in the AGCM are not included. 

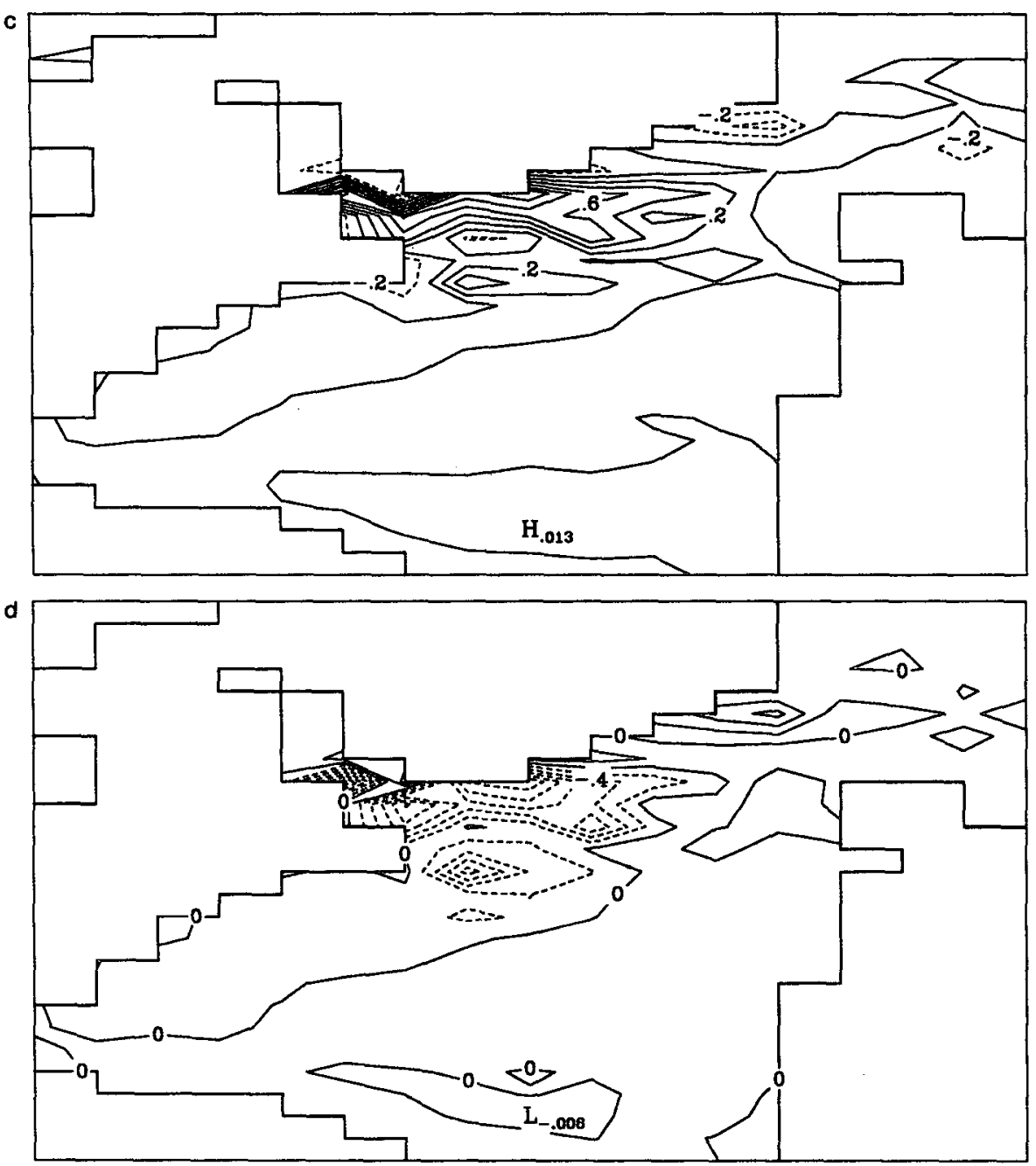

FIG. 12. (Continued)

Since the change in the net radiation is nearly linear in the AGCM (not shown), the reason lies with other model simplifications in SAM, namely the omission of changes in the background winds and in the use of an unchanging and simplistic eddy diffusion. In reality the winds do change. Furthermore, the functional form of the eddy parameterization is probably not perfectly satisfactory nor is the use of a simplistic parameterization of transient eddies. It is conceivable that the formulation (e.g., the specification of the spatial dependence of the eddy diffusion coefficient) is mean state dependent. In fact, this is supported by the standard deviation of the surface heat flux anomalies (not shown ) having a different spatial structure in the three runs (i.e., the control and the experiments in which single and double anomalies were imposed ). Note that stability-dependent drag coefficients are employed in both models but this does not give rise to significant nonlinearity in SAM. So the transition from stable to unstable conditions is probably not a crucial factor in determining the nonlinear response exhibited by the AGCM, unless this occurs when high-frequency variability is resolved.

\section{c. Scale dependence of the response}

As noted earlier, a number of studies have suggested that the damping rate applied to a given SST anomaly should be a function of its spatial structure. For example, the response of SAM to tropical SSTs was shown to depend upon the scale of the SST anomaly (Kleeman and Power 1995). Given that the response probably depends on the latitude where the anomaly is imposed (Phillips and Semtner 1984), these results do not necessarily carry over to higher latitudes. To see if there is a scale dependence at midlatitudes the SST we will consider the extreme example by reducing the SST by the same amount over the entire global ocean. The heat flux response, its various components, and $\kappa$ (for a $-2^{\circ} \mathrm{C}$ anomaly) 

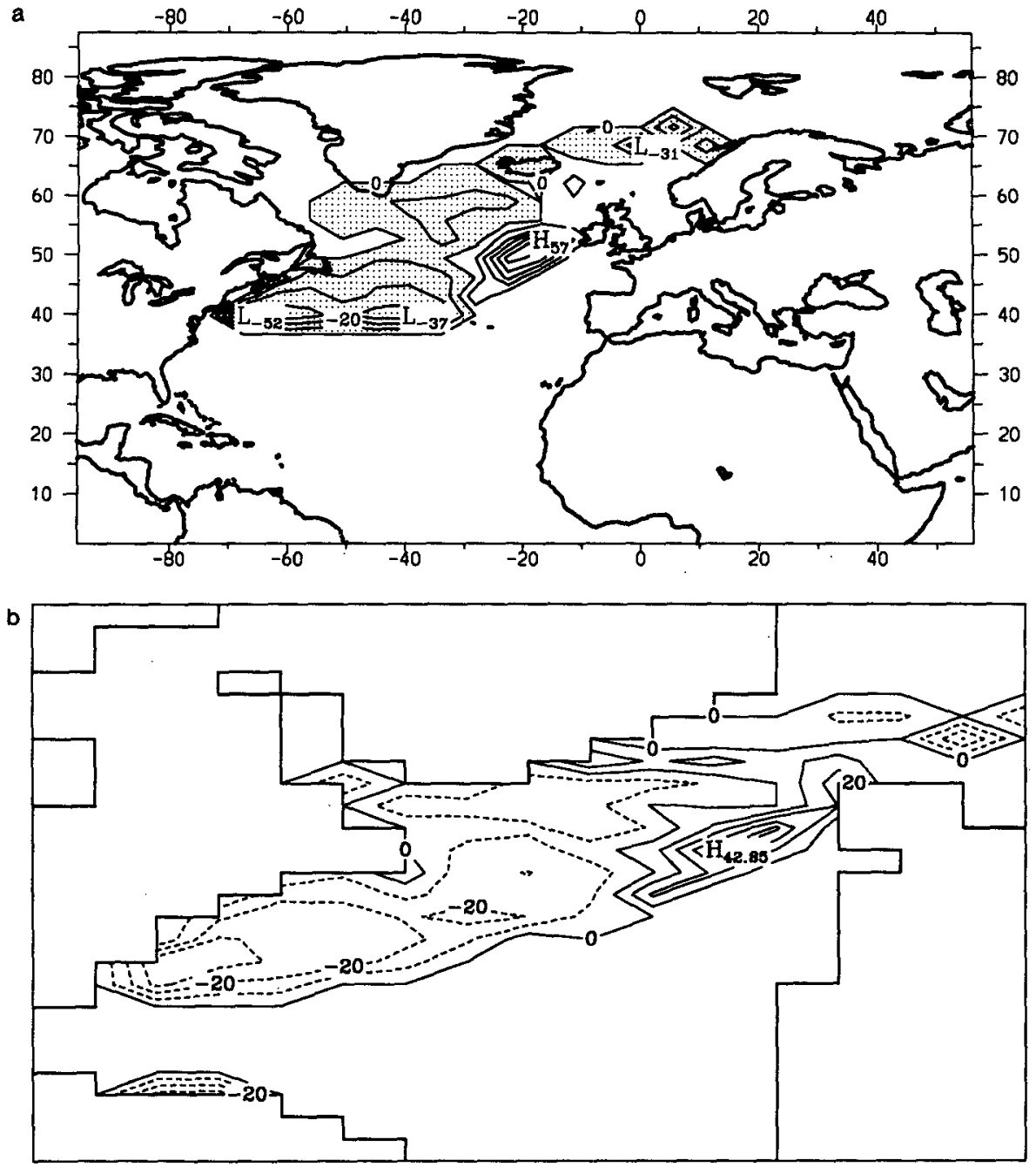

FIG. 13. Coefficient $\kappa$ diagnosed from (a) the AGCM and (b) SAM in response to the double SST anomaly. Units: $\mathrm{W} \mathrm{m}^{-2}{ }^{\circ} \mathrm{C}^{-1}$.

are presented in Fig. 14. Here $\kappa$ ranges from about $-1 \mathrm{~W} \mathrm{~m}^{-2}{ }^{\circ} \mathrm{C}^{-1}$ up to $-16 \mathrm{~W} \mathrm{~m}^{-2}{ }^{\circ} \mathrm{C}^{-1}$ over the Gulf Stream with a mean of about $-7 \mathrm{~W} \mathrm{~m}^{-2}{ }^{\circ} \mathrm{C}^{-1}$. A typical value for the restricted anomaly was about $-15 \mathrm{~W} \mathrm{~m}^{-2}{ }^{\circ} \mathrm{C}^{-1}$, so the restoration is approximately halved, though again there is a great deal of spatial variability. This is in qualitative agreement with the results from the simple analytic model considered earlier; however, the restoration is larger than estimates based on radiative relaxation alone (Zhang et al. 1993). The reason for this is that the magnitude of the surface temperature response over land is generally less than the imposed SST change. This causes land-sea contrasts in the response, so advection and diffusion are still able to modify the air temperature over the ocean, especially near continental boundaries. This leads to an enhanced heat flux response, and the contrasting response effectively places a lower bound on the scale dependence of $\kappa$.

\section{d. Impact of sea ice changes}

In the previous experiment the altered SST exhibited additional points at which sea ice should have formed. In order to determine the impact of changed sea ice conditions the experiment was repeated with sea ice extents consistent with the new SST distribution.

In the previous experiment, the heat provided by the ocean to the atmosphere over the Greenland-Iceland-Norwegian Sea (Fig. 1) was moderated because the atmosphere had a temperature closer to that of the ocean in the region. The introduction of sea ice enhanced this effect at the sea ice points but diminished it over the water adjacent to new sea ice. This is because the sea ice, which has 2-m thickness, insulates the ocean and drives the air temperature over the ice down, raising the temperature contrast between the atmosphere over the new ice and adjacent water, which increases the diffusion of heat in the atmosphere from over the 
ocean to over the ice. The SWR changes were found to be of secondary importance. This is partially due to an imposed 2-m thickness. To see why this is so, consider the following simple model of the atmospheric temperature near the ice edge where heat transport is accomplished by diffusion; that is,

$$
0=r\left(T^{*}-T\right)+\nu T_{x x}+F .
$$

The forcing term $F$ is used to represent the net radiative loss of heat to space over the sea ice by forcing $T \rightarrow$ $\underline{T}$ as $x \rightarrow-\infty$ over the sea ice. The solution to (8) takes the form

$$
T(x)=\left\{\begin{array}{l}
\underline{T}\left(1+H e^{\mu x}\right), \quad x<0 \\
T_{s}\left(1-\gamma \underline{T} H e^{-\gamma x} /\left(\gamma T_{s}\right)\right), \quad x \geqslant 0,
\end{array}\right.
$$

where $H=\left(T_{s} / \underline{T}-1\right) /(1+\mu / \gamma), \underline{T}$ is the (imposed) temperature at very high latitudes over the ice, $\mu^{2}$ $=\nu / r$, and $T_{s}$ is the (imposed) ocean temperature away from the ice. The solution is depicted in Fig. 15 for three different ice thicknesses: $0.01 \mathrm{~m}, 0.1 \mathrm{~m}$, and 2.0 $\mathrm{m}$ for $T=-10^{\circ} \mathrm{C}, T_{s}=2^{\circ} \mathrm{C}$, and $\nu=3.0 \times 10^{6} \mathrm{~m}^{2} \mathrm{~s}^{-1}$. The thick ice insulates the ocean, producing colder temperatures there and over the ocean nearby. The heat flux out of the ocean into the ice (Fig. 15b) is substantially reduced for thick ice, whereas the heat flux out of the uncovered ocean is increased. This reduces the restoration (since $k<0$ is increased) in the second experiment relative to the first, away from the ice, but increases $\Delta Q$ at the new ice locations. Note that the change in SWR in SAM would have been the same for thinner ice, and so $\triangle S W R$ would have become relatively more important to the heat budget if thinner ice had been introduced.

\section{e. Freshwater flux feedback}

So far our attention has been primarily restricted to the heat flux feedback. Here we wish to determine if there has been a significant change in the freshwater exchange with the North Atlantic. An increase in $R$ $+P-E$ would tend to provide a positive feedback on the initial perturbation discussed earlier.

The evaporation response is found to be consistent with the latent heat response (Fig. $3 b$ ). It has decreased over most of the anomaly (peaking at $0.78 \mathrm{~mm} \mathrm{day}^{-1}$ ), but increased toward the eastern flank (up to 0.43 $\mathrm{mm}$ day $^{-1}$ ), penetrating into the Mediterranean and to the northeast and southeast. The largest changes exhibited in the precipitation are centered on $45^{\circ} \mathrm{N}$, $40^{\circ} \mathrm{W}$ with a reduction peaking at $0.83 \mathrm{~mm} \mathrm{day}^{-1}$. This is offset by an increase surrounding this reduction over the North Atlantic from the southwest all the way around to the northeast extending into the Arctic. The peak in this surrounding band is near $30^{\circ} \mathrm{N}, 45^{\circ} \mathrm{W}$. The $P-E$ change is patchy with changes of both signs over the North Atlantic and its catchment areas, in- dicating that the changes in precipitation tend to compensate for most of the change in evaporation locally.

In order to see if the total freshwater exchange has been altered, $R+P-E$ was integrated over the North Atlantic and its catchment areas in the control, single, and double anomaly experiments for each month of the run. The mean freshwater fluxes and the interannual standard deviations for the three experiments are -0.27 and $0.05 \mathrm{~mm} \mathrm{day}^{-1}$ (control), -0.27 and 0.06 $\mathrm{mm} \mathrm{day}{ }^{-1}$ (single anomaly), and -0.26 and 0.05 $\mathrm{mm}$ day $^{-1}$ (double anomaly). The negative values indicate that there is a net divergence of freshwater out of the Atlantic, consistent with other modeling studies and with our understanding of the thermohaline circulation (e.g., Broecker et al. 1985). However, the difference between the double anomaly and control runs is not statistically significant at the $95 \%$ level, and so we cannot conclude that the anomalies imposed have a significant impact on the basin-scale freshwater balance for the SST anomalies considered.

These figures do not include the Arctic. When it is included the average freshwater flux becomes -0.136 $\mathrm{mm} \mathrm{day}{ }^{-1}$ in the control, indicating that the convergence of freshwater into the Arctic offsets the total divergence. This is again consistent with ocean model studies (e.g., Power et al. 1994) and with observational estimates (Aagaard and Carmack 1989). This gives us some degree of confidence in the AGCM's ability to model the basin's hydrological cycle, despite the possible existence of errors which arise from the spectral truncation of the precipitation field (Rasch and Williamson 1991).

\section{Discussion and conclusions}

An atmospheric general circulation model (AGCM), a simplified atmospheric model (SAM) of surface heat flux, and various idealized analytic models have been used to investigate the atmospheric response over the North Atlantic to sea surface temperature anomalies. Most attention centered on the heat flux response to a SST anomaly derived from an ocean modeling study (Power and Kleeman 1994) in which the thermohaline circulation or "conveyor belt" was reduced in strength. This reduction resulted in a general cooling over the North Atlantic to the south of Greenland.

The heat flux response was found to be generally restorative but exhibited a great deal of spatial variability. The response coefficient, $\kappa=-\Delta Q / \Delta T$, ranged from about -60 to $110 \mathrm{~W} \mathrm{~m}^{-2}{ }^{\circ} \mathrm{C}^{-1}$ with a characteristic value of around $-15 \mathrm{~W} \mathrm{~m}^{-2}$ in the AGCM. (Note that these figures were obtained by considering points where the SST anomaly imposed had a magnitude exceeding $0.125^{\circ} \mathrm{C}$. More extreme values of $\kappa$ could have been obtained if smaller anomalies had been considered.) Since $Q$ is taken here to be positive if the heat is out of the ocean, the positive value for $\kappa$ indicates that there is an enhancement of the SST anomaly in 

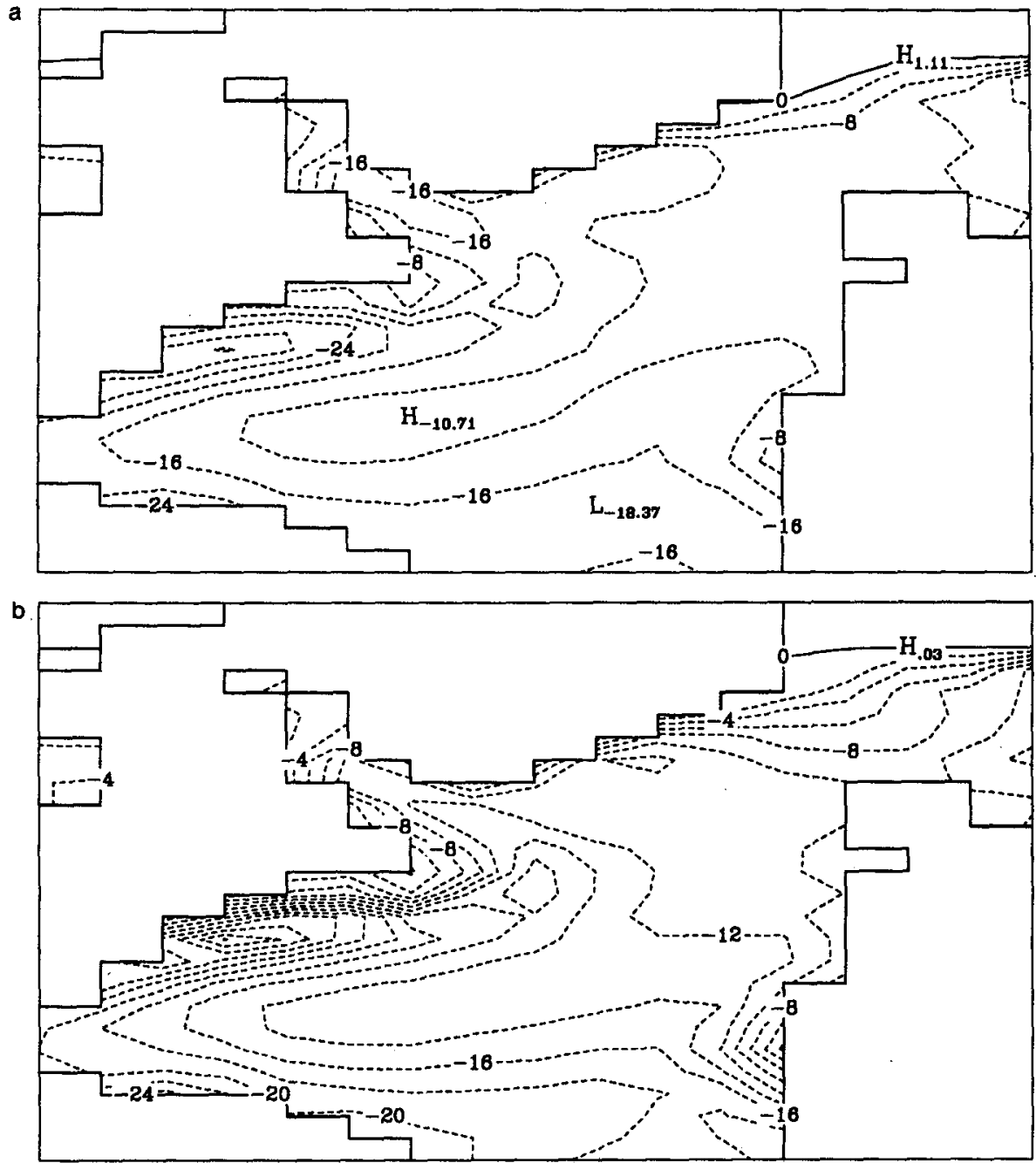

FIG. 14. The heat flux response in SAM to a global SST anomaly of $-2^{\circ} \mathrm{C}$ : (a) total, (b) latent, (c) sensible, (d) net LWR, and (e) $\kappa$. Units: $\mathrm{W} \mathrm{m}^{-2}$ in (a)-(d) and $\mathrm{W} \mathrm{m}^{-2}{ }^{\circ} \mathrm{C}^{-1}$ in (e).

certain places; $\Delta Q$ is also nonzero away from the SST anomaly, especially downwind toward the east, consistent with the earlier hypothesis by Frankignoul (1985). The response is dominated by the latent heating, with sensible heating the second most important response. All three models exhibit nonrestorative behavior away from the anomaly peak. In the AGCM, SAM, and the analytic model with advective transport only it is due to the advection of cooled air eastward. This simple picture is complicated in the AGCM by the fact that the winds weaken over the SST anomaly, which helps to moderate the response.

Analytic models are used to show the conditions under which a nonrestorative response can arise via advective or diffusive processes. The behavior arises if the transport process occurs on a length scale that exceeds the length scale of the SST anomaly. Additionally, the anomaly has to have a nonperiodic structure for nonrestorative behavior to occur via diffusive processes alone. The scale dependence of the diffusive solution for a periodic anomaly is shown to carry over to more localized anomalies when both advective and diffusive processes transport heat in the atmosphere.

The scale dependence of SAM's response was shown to be limited because land surface temperatures do not change by as much as the imposed SST anomalies. This allows both advection and diffusion in the model atmosphere to play a role in determining the restoration over the ocean (especially near coastal boundaries), even if the SST is altered by the same amount over the entire globe. It is interesting to note, however, that when AGCMs are forced in a similar fashion as part of feedback analysis experiments (FANGIO, Cess et al. 1990) the continental response in surface temperature over land is generally larger than that in SAM. This is believed to be due to enhanced continental precipitation, which results from increased moisture transport originating over the ocean (Déqué and Royer 1991). This 

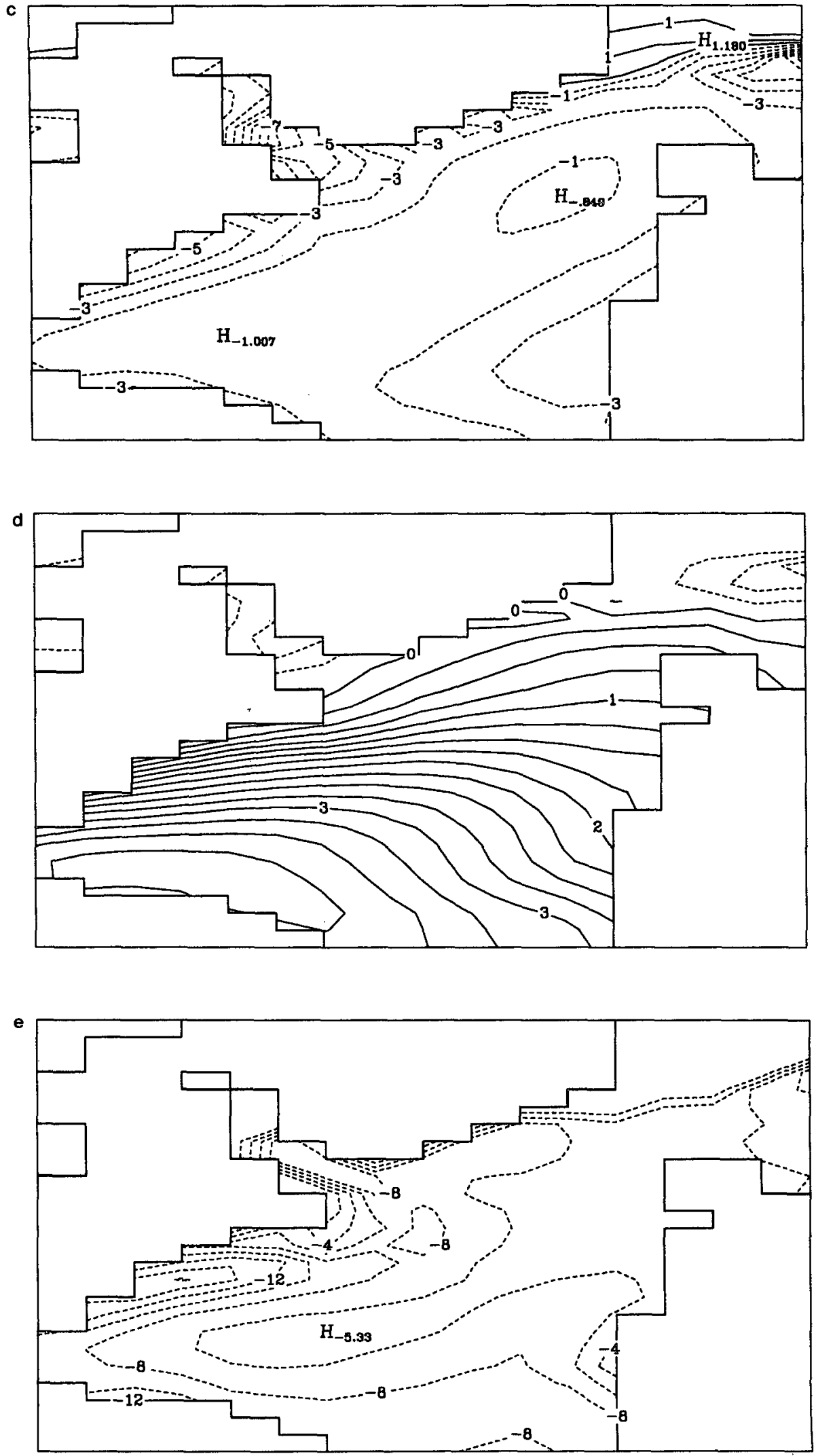

FIG. 14. (Continued) 

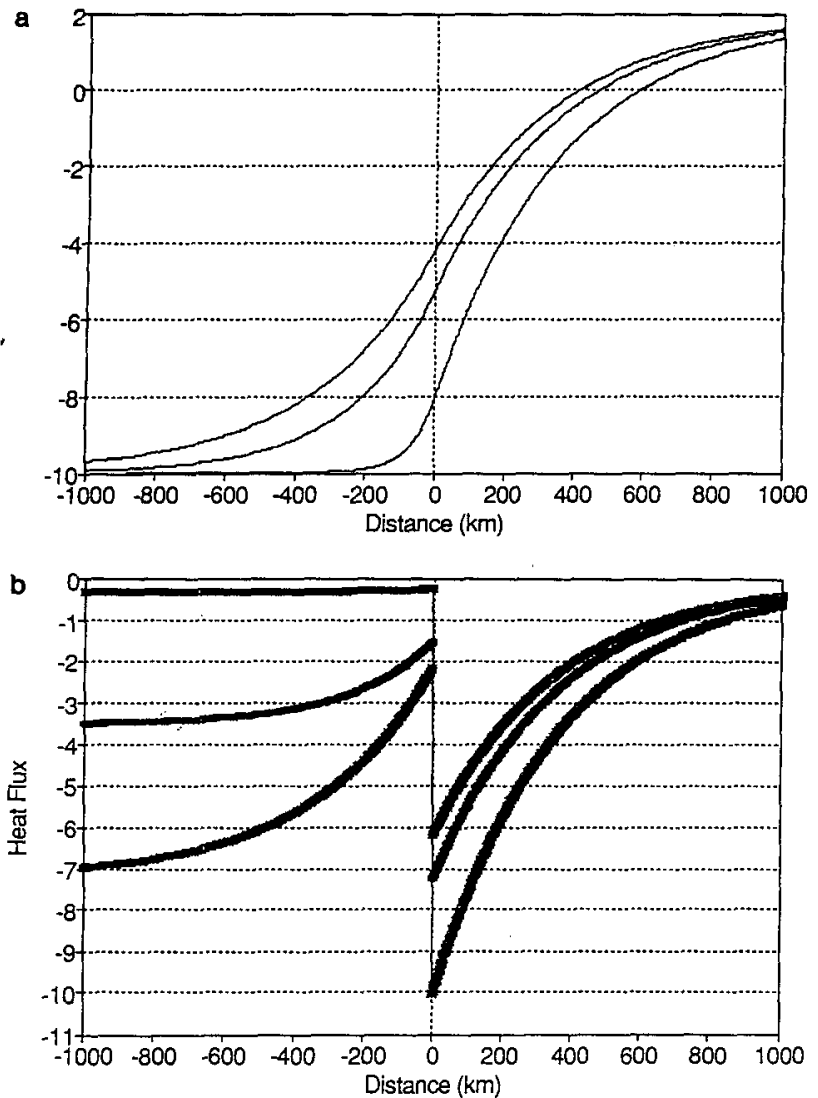

Fig. 15. Analytic solution to $0=r\left(T^{*}-T\right)+\nu T_{x x}+F$, with seaice at $x<0$ and open ocean at $x \geqslant 0 ; r=2^{\circ} \mathrm{C} \mathrm{day}^{-1} ; \nu=3.0 \times 10^{6}$ $\mathrm{m}^{2} \mathrm{~s}^{-1}$; and $h=0.01,0.1$, and $2.0 \mathrm{~m}$. (a) Air temperature and (b) surface heat flux.

effect is absent in SAM, so the enhanced response is probably overestimated. The inclusion of this effect into SAM would be a worthwhile exercise.

It is also worth noting that while global-scale anomalies are sometimes discussed to help understand the atmospheric response to climate variability and climate change, the SST distributions obtained from these models are rarely of the one sign over the entire globe. As a result, advection and diffusion can be expected to play additional roles in the response.

The inclusion of additional sea ice, consistent with imposed negative SST anomalies, was found to enhance the restoration at new sea ice points but reduce it over the ocean nearby. The introduction of sea ice partially insulated the underlying ocean from the atmosphere and thereby reduced the sensible heating there. This resulted in a drop in the surface temperature and overlying atmospheric temperature, which in turn led to an increase in the diffusive heat flux from farther south in SAM. This increase was maintained by an increase in the amount of heat leaving the ocean. A simple analytic model was used to show how the relative importance of the insulation to the $\triangle S W R$ as- sociated with the appearance of new sea ice increases with sea ice thickness.

The response of SAM was shown to be linear so that $\kappa$ did not change substantially if the magnitude of the anomaly was either doubled or halved. The AGCM exhibited some nonlinearity in the form of a generally reduced $|\kappa|$ due to a weakening of the winds over the anomaly and a somewhat reduced downwind response.

Recent work by Deser and Blackmon (1993) and Kushnir (1994) indicate that the SST variability in the North Atlantic seems to be predominantly driven by atmospheric forcing up to timescales as long as decadal but found evidence for the ocean variability driving an atmospheric response on interdecadal timescales. The results presented here can therefore be readily related to these much longer timescales. They are also of relevance on shorter timescales because atmospheric feedbacks play a role in the modification of SST anomalies once they are established and not all of the observed SST variability can be explained in terms of an oceanic response to atmospheric forcing.

The results obtained by imposing various SST anomalies indicate that the restoration is generally much weaker than that used in early attempts to model the oceans response to imposed freshening, confirming the concerns raised recently in this context (e.g., Power and Kleeman 1993, 1994; Zhang et al. 1993; Power et al. 1994), and is consistent with the results obtained in earlier AGCM studies (e.g., Frankignoul 1985; Rind et al. 1986). We also saw that the response coefficient is a function of the structure of the SST anomaly imposed and that a partial nonrestorative response is the rule rather than the exception. There is, however, some uncertainty attached to which of these differences are of crucial importance in determining the stability of the thermohaline circulation. Certainly if restoration is used, then it should be done using $\kappa$ smaller in magnitude than in the past, indicating that the system is indeed more stable than earlier thought (see also Power and Kleeman 1994). The importance of the remaining differences remains to be tested. Wright and Stocker (1993), for example, have been able to provide a good simulation of events before, during, and after the Younger Dryas, coupling their zonally averaged ocean model (Wright and Stocker 1991) to simplified atmospheric (and sea ice) configurations (Stocker et al. 1992). The key to their success lay in a modest adjustment to the freshwater balance of the model. They were able to stabilize their model to imposed freshening by enhancing the divergence of freshwater out of the Atlantic without further modification of the energy balance heat flux formulation. So it is possible that only a subset of the effects studied here are required to provide a reasonable assessment of the stability. We hope to investigate this in a future study using SAM coupled to the OGCM described earlier.

Finally, we saw that the freshwater budget response of the AGCM to the cooled SST conditions did not 
include any statistically significant change to the net divergence of freshwater from the North Atlantic and its catchment areas. There were significant local changes and so it is possible that these feedbacks may be important in modifying rates and positions of deep oceanic convection. In the Labrador Sea, for example, convection will tend to be promoted in those regions where $\Delta(E-P)$ is positive but reduced where it is negative. So if these regional changes play a significant role on the basin scale [as can occur in OGCMs under mixed BCs (e.g., Weaver et al. 1993)], then the feedback could be important.

The absence of a statistically significant difference in the basin-averaged $P-E$ is in stark contrast to the results obtained by Rind et al. (1986). This is probably because they imposed a SST anomaly with a much larger magnitude (about $10^{\circ} \mathrm{C}$ ) than we did (about $2^{\circ} \mathrm{C}$ ). Although given the variation in sensitivity from one AGCM to another to other types of perturbations (e.g., Cess et al. 1990), the possibility of a genuine difference in model behavior cannot be ruled out.

Acknowledgments. We wish to thank Rob Dahni for running the AGCM and archiving the output in a form suitable for subsequent analysis and both Dale Hess and Brian Sanderson for reviewing earlier drafts.

\section{APPENDIX}

\section{Solution of Equation (1) for SST $=\underline{T} \cos (k x)$}

If $T^{*}=T \operatorname{Re}\{\exp (i k x)\}$, then (2) has a solution

$$
T(x)=r T \operatorname{Re}\left\{\exp (i k x) /\left(i k u+k^{2} \nu+r\right)\right\},
$$

which can be used to construct the solution to arbitrary $T^{*}(x)$, providing it has a Fourier integral. Equation (A1) reduces to

$$
T(x)=r^{2} T \operatorname{Re}\{(1-i u k / r) \exp (i k x)\} /\left(r^{2}+k^{2} u^{2}\right)
$$

if $\nu=0$ and

$$
T(x)=(r T / \nu) \cos (k x) /\left(k^{2}+r^{2} / \nu^{2}\right)
$$

if $u=0$. The purely diffusive solution (A3) has ( $T$ $\left.-T^{*}\right) / T^{*}=-1 /\left(1+r^{2} / \nu^{2} k^{2}\right)$, so it is restorative at all positions for which $T^{*} \neq 0$ regardless of the length scale of the anomaly. The restoration has a magnitude that increases as the length scale of the SST anomaly is reduced and as $\nu$ is increased, but never exceeds unity. The purely advective response (A2) restores the anomaly in parts but amplifies it in others. This is not the case for short scales for which $k \gg 1 /(r u)$. The advective solution is then purely restorative and becomes increasingly so at shorter scales.

\section{REFERENCES}

Aagaard, K., and E. C. Carmack, 1989: The role of sea ice and other freshwater in the Arctic circulation. J. Geophys. Res., 94, 14 48514498.
Bourke, W. P., 1987: Spectral methods in global climate and weather prediction models. The Physical Basis of Climate Modelling, M. E. Schlesinger, Ed., NATO ASI Series, D. Reidel, 375-431.

- B. J. McAvaney, K. Puri, and R. Thurling, 1977: Global modelling of atmospheric flow by spectral methods. General circulation models of the atmosphere. Methods in Computational Physics, Vol. 17, J. Chang, Ed., Academic Press, 267-324.

Bretherton, F. P., 1982: Ocean climate modeling. Progress in Oceanography, Vol. 11, Pergamon, 93-129.

Broecker, W. S., D. M. Peteet, and D. Rind, 1985: Does the oceanatmosphere system have more than one stable mode of operation? Nature, 315, 21-26.

Bryan, F., 1986: High-latitude salinity effects and Ointerhemispheric thermohaline circulations. Nature, 323, 301-304.

Bryan, K., 1969: A numerical method for the study of the circulation of the world ocean. J. Comput. Phys., 4, 347-376.

, and L. J. Lewis, 1979: A water mass model of the world ocean. J. Geophys. Res., 84, 347-376.

Cayan, D. R., 1990: Variability of latent and sensible heat fluxes over the oceans. Ph.D. dissertation, University of California, San Diego, $199 \mathrm{pp}$.

- 1992: Latent and sensible heat flux anomalies over the northern oceans: The connection to monthly atmospheric circulation. $J$. Climate, 5, 354-369.

Cess, R. D., and Collaborators, 1990: Intercomparison and interpretation of climate feedback processes in 19 atmospheric general circulation models. J. Geophys. Res., 95, 16 601-16 615 .

CLIMAP Project Members, 1981: Seasonal reconstruction of the earth's surface at the last glacial maximum. Geol. Soc. Amer. Map Chart Ser., MC-36.

Cox, M., 1984: A primitive equation, three-dimensional model of the ocean. GFDL Ocean Group Tech. Rep. No. 1, GFDL/ Princeton, $376 \mathrm{pp}$.

Déqué, M., and J. F. Royer, 1991: GCM response of the mean zonal surface heat and water budgets to a global sea surface temperature anomaly. Dyn. Atmos. Oceans, 16, 133-146.

Deser, C., and M. L. Blackmon, 1993: Surface climate variations over the North Atlantic during winter 1900-1989. J. Climate, 6, 1743-1753.

Duplessy, J. C., L. Labeyrie, M. Arnold, M. Paterne, J. Duprat, and T. C. E. van Weering, 1992: Changes in the surface salinity of the North Atlantic Ocean during the last deglaciation. Nature, 358, 485-488.

Fels, S. B., and M. D. Schwarzkopf, 1975: The simplified exchange approximation: A new method for radiative transfer calculations. J. Atmos. Sci., 32, 1475-1488.

Frankignoul, C., 1985: Sea surface temperature anomalies, planetary waves, and air-sea feedback in the middle latitudes. Rev. Geophys., 23, 357-390.

Gildor, H., I. Rivin, and E. Tziperman, 1994: A test case for mixed boundary conditions for ocean models as an approximation to full ocean-atmosphere coupling. J. Phys. Oceanogr., submitted.

Gill, A. E., 1982: Atmosphere-Ocean Dynamics, Academic Press, 662 pp.

Hart, T. L., M. J. Gay, and W. P. Bourke, 1988: Sensitivity studies with the physical parameterisations in the BMRC global atmospheric spectral model. Aust. Meteor. Mag., 36, 47-60.

- W. P. Bourke, B. J. McAvaney, B. W. Forgan, and J. L. McGregor, 1990: Atmospheric general circulation simulations with the BMRC global spectral model: The impact of revised physical parameterisations. J. Climate, 3, 436-459.

Hellerman, S., and M. Rosenstein, 1983: Normal monthly wind stress over the world ocean with error estimates. J. Phys. Oceanogr., 13, 1093-1104.

Kleeman, R., and S. B. Power, 1995: A simple atmospheric model of surface heat flux for use in ocean modeling studies. J. Phys. Oceanogr., 25, 92-105.

Kushnir, Y., 1994: Interdecadal variations in North Atlantic sea surface temperature and associated atmospheric conditions. $\mathrm{J}$. Climate, 7, 141-157. 
- , and N.-C. Lau, 1992: The general circulation model response to a North Pacific SST anomaly: Dependence on time scale and polarity. J. Climate, 1, 500-511.

Lau, N.-C., and M. J. Nath, 1990: A general circulation model study of the atmospheric response to extratropical SST anomalies observed in 1950-79. J. Climate, 3, 965-989.

Levitus, S., 1982: Climatological Atlas of the World Ocean. NOAA Prof. Paper 13, $173 \mathrm{pp}$.

Louis, J.-F., M. Tiedtke, and M. Geleyn, 1982: A short history of the PBL parameterization at ECMWF. Proc., ECMWF Workshop on Planetary Boundary Layer Parameterization, Reading, U.K., ECMWF, 59-80.

McAvaney, B. J., and R. A. Colman, 1993: The AMIP Experiment: The BMRC AGCM configuration. BMRC Res. Rep. No. 38, $43 \mathrm{pp}$.

—_W. P. Bourke, and K. Puri, 1978: A global spectral model for simulation of the general circulation. J. Atmos. Sci., 35, 15571583.

- J. R. Fraser, T. L. Hart, L. J. Rikus, W. P. Bourke, M. J. Naughton, and P. Mullenmeister, 1991: Circulation statistics from a non-diurnal seasonal simulation with the BMRC Atmospheric GCM. BMRC Res. Rep. No. 29, 231 pp.

Mikolajewicz, U., and E. Maier-Reimer, 1994: 'Mixed boundary conditions' in OGCMs and their influence on the stability of the model's conveyor belt. Max Planck Institute for Meteorology, Hamburg, Rep. No. 130, 24 pp.

Miller, M. J., A. C. M. Beljaars, and T. N. Palmer, 1992: The sensitivity of the ECMWF model to the parameterization of evaporation from the tropical ocean. J. Climate, 5, 418-434.

Nakamura, M., P. H. Stone, and J. Marotzke, 1994: Atmospheric coupling for freshwater and heat fluxes in ocean box models. $J$. Climate, 7, 1870-1882.

Namias, J., and D. R. Cayan, 1981: Large-scale air-sea interactions and short-period climatic fluctuations. Science, 214, 869-876.

Oberhuber, J., 1988: An atlas based on the COADS data set: The budgets of heat, buoyancy and turbulent kinetic energy at the surface of the global ocean. Max Planck Institute for Meteorology, Rep. No. 15.

Pacanowski, R. C., K. Dixon, and A. Rosati, 1991: The GFDL Modular Ocean Model Users Guide, version 1.0, GFDL Ocean Group Tech. Rep. No. 2, 376 pp.

Palmer, T. N., and Z. Sun, 1985: A modelling and observational study of the relationship between sea surface temperature in the north-west Atlantic and the atmospheric general circulation. Quart. J. Roy. Meteor. Soc., 111, 947-975.

- G. J. Shutts, and R. Swinbank, 1986: Alleviation of a systematic bias in general circulation and numerical weather prediction models through an orographic gravity wave drag parameterization. Quart. J. Roy. Meteor. Soc., 112, 1001-1039.

Peng, S., and L. A. Mysak, 1993: A teleconnection study of interannual sea surface temperature fluctuations in the northern North Atlantic and precipitation anomalies over western Siberia. J. Climate, 5, 876-885.

Phillips, T. J., and A. J. Semtner Jr., 1984: The seasonal response of the Held-Suarez climate model to prescribed ocean temperature anomalies. Part I: Results of decadal integrations. J. Atmos. Sci., 41, 2605-2619.
Power, 1995: Climate drift in a global ocean general circulation model. J. Phys. Oceanogr., 25, 1025-1036.

- , and R. Kleeman, 1993: Multiple equilibria in a global ocean circulation model. J. Phys. Oceanogr., 23, 1670-1681.

- and - 1994: Surface heat flux parameterization and the response of OGCMs to high latitude freshening. Tellus, 46A, 86-95.

- R. A. Colman, B. J. McAvaney, R. R. Dahni, A. M. Moore and N. R. Smith, 1993: BMRC coupled atmosphere/ocean/ sea-ice model. BMRC Res. Rep. No. 37, 58 pp.

-_, A. M. Moore, D. A. Post, N. R. Smith, and R. Kleeman, 1994: Stability of North Atlantic Deep Water Formation in a global OGCM. J. Phys. Oceanogr., 24, 904-916.

Rahmstorf, S., and J. Willebrand, 1995: The role of temperature feedback in stabilizing the thermohaline circulation. J. Phys. Oceanogr., 25, 787-805.

Rasch, P. J., and D. L. Williamson, 1991: Sensitivity of a general circulation model climate to the moisture transport formulation. J. Geophys. Res., 96, 123-137.

Ratcliffe, R. A. S., and R. Murray, 1970: New lag associations between North Atlantic sea temperature and European pressure applied to long-range weather forecasting. Quart. J. Roy. Meteor. Soc., 96, 226-246.

Rind, D., D. Peteet, W. Broecker, A. McIntyre, and W. Ruddiman, 1986: The impact of cold North Atlantic sea surface temperatures on climate: Implications for the Younger Dryas cooling (1110k). Climate Dyn., 1, 3-33.

Schopf, P. S., 1985: Modeling tropical sea-surface temperature: Implications of various atmospheric responses. Coupled OceanAtmosphere Models, J. C. J. Nihoul, Ed., Elsevier, 727-734.

Stocker, T. F., D. G. Wright, and L. A. Mysak, 1992: A zonally averaged, coupled ocean-atmosphere model for paleoclimate studies. J. Climate, 5, 773-797.

Tiedtke, M., 1984: The sensitivity of the time mean large-scale flow to cumulus convection in the ECMWF model. Report of Workshop on Convection in Large-scale Numerical Models, ECMWF, Shinfield Park, Reading, U.K., 297-316.

__ 1989: A comprehensive mass flux scheme for cumulus parameterization in large-scale models. Mon. Wea. Rev., 117, 17791800 .

Walpole, R. E., and R. H. Myers, 1990: Probability and Statistics. Fourth ed., Macmillan, 765 pp.

Wang, H., and G. E. Birchfield, 1992: Atmospheric water vapor flux, bifurcation of the thermohaline circulation, and climate change. Climate Dyn., 8, 49-53.

Weaver, A. J., J. Marotzke, P. F. Cummins, and E. S. Sarachik, 1993: Stability and variability of the thermohaline circulation. J. Phys. Oceanogr., 23, 39-60.

Woodruff, S. D., R. J. Slutz, R. L. Jenne, and P. M. Steurer, 1987: A comprehensive ocean-atmosphere data set. Bull. Amer. $M e$ teor. Soc., 68, 1239-1250.

Wright, D. G., and T. F. Stocker, 1991: A zonally averaged ocean model for the thermohaline circulation. Part I: Model development and flow dynamics. J. Phys. Oceanogr., 21, 1713-1724.

- and - 1993: Younger Dryas experiments. Ice in the Climate System, W. R. Peltier, Ed., NATO ASI Series I 21, 395-416.

Zhang, S., R. J. Greatbatch, and C. A. Lin, 1993: A re-examination of the polar halocline catastrophe and implications for coupled ocean-atmosphere modeling. J. Phys. Oceanogr., 23, 287-299. 